\title{
Sensitivity of satellite observations for freshly produced lightning $\mathrm{NO}_{\mathrm{x}}$
}

\author{
S. Beirle ${ }^{1}$, M. Salzmann ${ }^{2}$, M. G. Lawrence ${ }^{1}$, and T. Wagner ${ }^{1}$ \\ ${ }^{1}$ Max-Planck-Institut für Chemie, (Otto Hahn Institute), Mainz, Germany \\ ${ }^{2}$ Atmospheric and Oceanic Sciences Program, Princeton University, Princeton, NJ, USA
}

Received: 12 August 2008 - Published in Atmos. Chem. Phys. Discuss.: 15 October 2008

Revised: 15 January 2009 - Accepted: 20 January 2009 - Published: 12 February 2009

\begin{abstract}
In this study, we analyse the sensitivity of nadir viewing satellite observations in the visible range to freshly produced lightning $\mathrm{NO}_{\mathrm{x}}$. This is a particular challenge due to the complex and highly variable conditions of meteorology, (photo-) chemistry, and radiative transfer in and around cumulonimbus clouds. For the first time, such a study is performed accounting for photo-chemistry, dynamics, and radiative transfer in a consistent way: A one week episode in the TOGA COARE/CEPEX region (Pacific) in December 1992 is simulated with a 3-D cloud resolving chemistry model. The simulated hydrometeor mixing ratios are fed into a Monte Carlo radiative transfer model to calculate box-Air Mass Factors (box-AMFs) for $\mathrm{NO}_{2}$. From these box-AMFs, together with model $\mathrm{NO}_{\mathrm{x}}$ profiles, slant columns of $\mathrm{NO}_{2}$ $\left(\mathrm{S}^{\mathrm{NO}_{2}}\right)$, i.e. synthetic satellite measurements, are calculated and set in relation to the actual model $\mathrm{NO}_{\mathrm{x}}$ vertical column

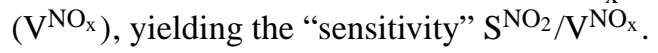

From this study, we find a mean sensitivity of 0.46 . $\mathrm{NO}_{\mathrm{x}}$ below the cloud bottom is mostly present as $\mathrm{NO}_{2}$, but shielded from the satellites' view, whereas $\mathrm{NO}_{\mathrm{x}}$ at the cloud top or above is shifted to NO due to high photolysis and low temperature, and hence not detectable from space. However, a significant fraction of the lightning produced $\mathrm{NO}_{\mathrm{x}}$ in the middle part of the cloud is present as $\mathrm{NO}_{2}$ and has a good visibility from space. Due to the resulting total sensitivity being quite high, nadir viewing satellites provide a valuable additional platform to quantify $\mathrm{NO}_{\mathrm{x}}$ production by lightning; strong lightning events over "clean" regions should be clearly detectable in satellite observations. Since the observed enhancement of $\mathrm{NO}_{2}$ column densities over mesoscale convective systems are lower than expected for current estimates of $\mathrm{NO}_{\mathrm{x}}$ production per flash, satellite measurements can in particular constrain the upper bound of lightning $\mathrm{NO}_{\mathrm{x}}$ production estimates.
\end{abstract}

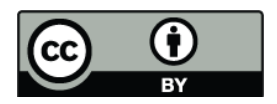

Correspondence to: $\mathrm{S}$. Beirle (beirle@mpch-mainz.mpg.de)

\section{Introduction}

Lightning $\mathrm{NO}_{\mathrm{x}}\left(\mathrm{LNO}_{\mathrm{x}}\right)$, suggested to be the dominant $\mathrm{NO}_{\mathrm{x}}$ source in the tropical upper troposphere (Schumann and Huntrieser, 2007, and references therein), plays an important role in atmospheric chemistry by driving ozone formation and influencing the $\mathrm{OH}$ concentration (e.g. Labrador et al., 2005). However, estimates of the total annual $\mathrm{NO}_{\mathrm{x}}$ release by lightning are still uncertain, and literature results differ significantly, though they seem to be converging on the range of $2-8 \mathrm{Tg}[\mathrm{N}]$ per year (Schumann and Huntrieser, 2007).

Satellite observations using nadir viewing spectrometers, like the Global Ozone Monitoring Experiment (GOME $1 \& 2)$, the SCanning Imaging Absorption Spectrometer for Atmospheric CHartographY (SCIAMACHY), or the Ozone Monitoring Instrument (OMI) (e.g. Burrows et al., 1999; Bovensmann et al., 1999; Levelt et al., 2006), that provide column measurements of $\mathrm{NO}_{2}$ on a global scale, allow a new approach to estimate $\mathrm{LNO}_{\mathrm{x}}$ production. Some studies have compared mean observed $\mathrm{NO}_{2}$ columns with lightning measurements (Beirle et al., 2004), flash rates parameterized from cloud top height (Boersma et al., 2005), or modelled $\mathrm{LNO}_{\mathrm{x}}$ distributions (Martin et al., 2007). Since lightning activity is highest over tropical land masses, and has its peak in the late afternoon, while current satellite instruments measure in the morning (GOME 1\&2, SCIAMACHY) or shortly after noon (OMI), these comparisons mainly detect aged $\mathrm{LNO}_{\mathrm{x}}$. Hence, for quantification of $\mathrm{LNO}_{\mathrm{x}}$ production, its lifetime has to be considered, which is also rather uncertain and strongly depending on altitude.

As an alternative to the approaches discussed above, it is also possible to study freshly produced $\mathrm{LNO}_{\mathrm{x}}$ directly over individual active thunderstorms occurring at satellite overpass. Within the long time series of satellite measurements with global coverage, several coincidences of lightning activity during satellite overpass are found, mostly over ocean,

Published by Copernicus Publications on behalf of the European Geosciences Union. 
where the diurnal cycle of flash activity is much smoother than over land, having the positive side effect that interference of other $\mathrm{NO}_{\mathrm{x}}$ sources is generally smaller. A prominent example has been described in Beirle et al. (2006). This new approach, which is investigated quantitatively in this study, has the advantage that chemical loss and dilution are negligible (with respect to temporal scales of some hours and spatial scales of typical current satellite footprints, i.e. hundreds to thousands of $\mathrm{km}^{2}$ ). Hence, the increase in $\mathrm{NO}_{\mathrm{x}}$ can directly be related to flash numbers, e.g., those from the World Wide Lightning Location Network (WWLLN) that are available continuously on global scale (Rodger et al., 2006).

The direct observation and quantification of $\mathrm{LNO}_{\mathrm{x}}$ over thunderstorms, however, is strongly affected by the presence of clouds. Generally, clouds shield trace gases below them from the satellite's view. On the other hand, clouds also increase the sensitivity for trace gases at the cloud top or above, due to multiple scattering and their high albedo, respectively. In addition, in the case of $\mathrm{NO}_{\mathrm{x}}$, clouds also affect photolysis, i.e. the partitioning of $\mathrm{NO}_{\mathrm{x}}$ into $\mathrm{NO}$ and $\mathrm{NO}_{2}$, while only the latter is detectable in satellite spectra. For quantitative estimates of these effects, radiative transfer modelling is needed.

Here we analyse the sensitivity of satellite observations for detecting $\mathrm{LNO}_{\mathrm{x}}$ under thunderstorm conditions. A cloud resolving model, accounting for dynamics and (photo-) chemistry, is used in combination with a Monte Carlo Radiative Transfer Model (RTM) to calculate synthetic satellite observations. Hence the satellite response to the $\mathrm{LNO}_{\mathrm{x}}$ which is actually produced can be quantified.

\section{Methods}

Satellite measurements of tropospheric trace gases, in particular of $\mathrm{NO}_{2}$, have been used to estimate and constrain emissions in several studies. In most of these studies, clouded observations are simply skipped, as clouds shield the boundary layer from the satellites' view. If one is interested in the observation of freshly produced $\mathrm{LNO}_{\mathrm{x}}$, however, skipping clouded pixels is not possible. Instead, one has to deal with the complications due to clouds.

From spectral satellite measurements, slant column densities (SCDs), i.e., concentrations integrated along the light paths, of $\mathrm{NO}_{2}$ can be derived. For quantitative interpretations, however, vertical column densities (VCDs), i.e., vertically integrated concentrations, of $\mathrm{NO}_{\mathrm{x}}$ are needed that can be directly related to emissions if loss due to chemistry and transport is small.

In Sect. 2.1, we derive a formalism to relate (excess) $\mathrm{NO}_{2}$ SCDs to (lightning) $\mathrm{NO}_{\mathrm{x}} \mathrm{VCDs}$, considering the specific conditions for lightning $\mathrm{NO}_{\mathrm{x}}$. The ratio of $\mathrm{NO}_{2} \mathrm{SCD}$ and $\mathrm{NO}_{\mathrm{x}} \mathrm{VCD}$ is denoted as "sensitivity" in this study and depends on the profiles of $\mathrm{NO}_{\mathrm{x}}$ and $\mathrm{NO}_{2}$, that are taken from a cloud resolving model (Sect. 2.2), as well as on boxAMFs (Air Mass Factors), that are calculated with an RTM
(Sect. 2.3) using the modelled cloud profiles. In Sect. 2.4, the final calculation of sensitivities and "synthetic" $\mathrm{NO}_{2} \mathrm{SCDs}$ for the temporal and spatial range covered by the model is described.

\subsection{Sensitivity of satellite observations for $\mathrm{NO}_{\mathrm{x}}$}

From UV-vis satellite measurements, slant column densities (SCDs), i.e., concentrations integrated along the light paths, can be derived for various trace gases (e.g., Wagner et al., 2008). For a quantitative interpretation, the SCD S has to be converted into the vertical column density (VCD) V, that represents the vertically integrated concentration. The ratio $\mathrm{S} / \mathrm{V}$ is given by the air mass factor (AMF) A:

$\mathrm{A}:=\mathrm{S} / \mathrm{V}$

The AMF reflects the sensitivity of the observation for the investigated trace gas, and depends on various parameters like solar zenith angle (SZA), ground albedo, aerosols and clouds. In particular, due to atmospheric scattering/absorption, the sensitivity is a function of altitude, determined by the actual profile of scattering/absorbing particles/molecules. Hence the total AMF depends on the trace gas profile. One possibility to account for this height dependence is the concept of "box-AMFs" $a_{i}$ (see Wagner et al., 2007), giving the AMF for a trace gas in layer $i$. The total AMF can then be expressed as the sum of the box-AMFs $a_{i}$, weighted by the normalized profile $p_{i}$ :

$\mathrm{S}=\mathrm{V} \cdot \sum_{i} p_{i} \cdot a_{i}$

where $i$ is the vertical layer index, and $p_{i}$ is the partial trace gas column in layer $i$, normalized according to

$\sum_{i} p_{i}=1$

Note that it is possible to directly calculate the partial column of a layer from the product of the mean concentration and mean height of that layer, and that for layers of equal thickness, the partial column and concentration profiles are proportional to each other.

In the case of $\mathrm{NO}_{\mathrm{x}}$, in contrast to other trace gases, additional complications arise from the fact that only $\mathrm{NO}_{2}$, but not NO, is detectable in the UV/vis spectral range. For a given $\mathrm{VCD}$ of $\mathrm{NO}_{\mathrm{x}}\left(\mathrm{V}^{\mathrm{NO}_{\mathrm{x}}}\right)$, the measured $\mathrm{SCD}$ of $\mathrm{NO}_{2}$ $\left(\mathrm{S}^{\mathrm{NO}_{2}}\right)$ would be

$\mathrm{S}^{\mathrm{NO}_{2}}=\mathrm{V}^{\mathrm{NO}_{\mathrm{x}}} \cdot \sum_{i} p_{i} \cdot a_{i} \cdot l_{i}$,

where $p_{i}$ is still the normalized $\mathrm{NO}_{\mathrm{x}}$ profile and

$l_{i}:=\frac{\left[\mathrm{NO}_{2}\right]_{i}}{\left[\mathrm{NO}_{\mathrm{x}}\right]_{i}}$

is the $\mathrm{NO}_{\mathrm{x}}$ partitioning in layer $i$. 
If the product of the box-AMF and the partitioning is defined as

$e_{i}:=a_{i} \cdot l_{i}$

it follows from Eq. (4) that

$\mathrm{S}^{\mathrm{NO}_{2}}=\mathrm{V}^{\mathrm{NO}_{\mathrm{x}}} \cdot \sum_{i} p_{i} \cdot e_{i}$,

and, with

$\mathrm{E}:=\sum_{i} p_{i} \cdot e_{i}$

follows

$\mathrm{S}^{\mathrm{NO}_{2}}=\mathrm{V}^{\mathrm{NO}_{\mathrm{x}}} \cdot \mathrm{E}$

in analogy to Eq. (1).

Hence, $e_{i}$ can be interpreted as the "effective box-AMF" for $\mathrm{NO}_{\mathrm{x}}$, and is called "visibility" hereafter. The overall conversion factor $\mathrm{E}$ is referred to as the "sensitivity". In this study, E will be calculated for conditions in and around cumulonimbus clouds, using $\mathrm{NO}_{\mathrm{x}}$ and $\mathrm{NO}_{2}$ profiles from a cloud resolving model (2.2) and box-AMFs modelled for the respective cloud profiles (2.3). Knowing E, "synthetic" slant columns of $\mathrm{NO}_{2}$ can be calculated from model profiles of $\mathrm{NO}_{2}$ and $\mathrm{NO}_{\mathrm{x}}$, simulating satellite measurements. The other way around, observed $\mathrm{S}^{\mathrm{NO}_{2}}$ derived from satellite observations can be converted into $\mathrm{V}^{\mathrm{NO}_{\mathrm{x}}}$, i.e. satellite $\mathrm{NO}_{2} \mathrm{SCDs}$ can be related to the actual $\mathrm{NO}_{\mathrm{x}}$ column via $\mathrm{E}$.

Please note that a two-step conversion (first from $\mathrm{NO}_{2}$ SCDs into $\mathrm{NO}_{2}$ VCDs using an overall AMF, and then from $\mathrm{NO}_{2}$ VCDs into $\mathrm{NO}_{\mathrm{x}} \mathrm{VCD}$ using a mean $\mathrm{NO}_{2} / \mathrm{NO}_{\mathrm{x}}$ ratio) is not appropriate, since both the box-AMFs and the $\mathrm{NO}_{\mathrm{x}}$ partitioning are height dependent, and they do not vary independently because both are particularly influenced by clouds.

In this study, we are interested in $\mathrm{NO}_{\mathrm{x}}$ produced by lightning $\left(\mathrm{LNO}_{\mathrm{x}}\right)$. The $\mathrm{LNO}_{\mathrm{x}} \mathrm{VCD}$ can be defined by

$\mathrm{V}^{\mathrm{LNO}_{\mathrm{x}}}:=\mathrm{V}^{\mathrm{NO}_{\mathrm{x}}}-\mathrm{V}^{0}$

with $\mathrm{V}^{0}$ being the appropriate "background" $\mathrm{NO}_{\mathrm{x}} \mathrm{VCD}$ (including the stratosphere), i.e. the column one would observe in absence of lightning.

Similarly, we define the $\mathrm{S}^{\mathrm{NO}_{2}}$ excess as

$\Delta \mathrm{S}^{\mathrm{NO}_{2}}:=\mathrm{S}^{\mathrm{NO}_{2}}-\mathrm{S}^{0}$.

Note that, in practice, the subtraction of the background column $S^{0}$ removes the tropospheric background and the stratospheric part of the column, but also accounts for uncertainties in the absolute calibration of SCDs (see e.g. Wenig et al., 2004).

In general, $\Delta \mathrm{S}^{\mathrm{NO}_{2}}$ is not just a response to the produced $\mathrm{LNO}_{\mathrm{x}}$ (and, hence, is not denoted as $\mathrm{S}^{\mathrm{LNO}_{2}}$ in Eq. (11)), since cumulonimbus clouds and convection also affect the visibilities and profiles, respectively, of background $\mathrm{NO}_{\mathrm{x}}$. In particular, background $\mathrm{NO}_{\mathrm{x}}$ in the lower troposphere is shielded effectively by high, optically thick clouds.
In analogy to Eq. (9), we define $\mathrm{S}^{\mathrm{LNO}_{2}}$ as

$\mathrm{S}^{\mathrm{LNO}_{2}}:=\mathrm{V}^{\mathrm{LNO}_{\mathrm{x}}} \cdot \mathrm{E}^{\mathrm{L}}$

with

$\mathrm{E}^{\mathrm{L}}:=\sum_{i} p_{i}^{\mathrm{L}} \cdot e_{i}^{\mathrm{L}}$,

i.e. using profiles of $\mathrm{LNO}_{\mathrm{x}}$ (background corrected) and visibilities calculated for the actual (possibly clouded) viewing conditions. In the following, the letter " $E$ " refers to sensitivities of lightning $\mathrm{NO}_{\mathrm{x}}$, even if the superscript ${ }^{\mathrm{L}}$ is omitted.

In this study, we calculate sensitivities for $\mathrm{LNO}_{\mathrm{x}}$ using Eq. (13) and derive synthetic SCDs of $\mathrm{LNO}_{2}$ by Eq. (12). In the appendix, a relationship between $\Delta \mathrm{S}^{\mathrm{NO}_{2}}$ and $\mathrm{S}^{\mathrm{LNO}_{2}}$ is derived. It is shown that $\mathrm{S}^{\mathrm{LNO}_{2}}$ can actually be approximated by $\Delta \mathrm{S}^{\mathrm{NO}_{2}}$ (i.e., the actual response to lightning $\mathrm{NO}_{\mathrm{x}}$ that a satellite would detect), if the tropospheric background levels of $\mathrm{NO}_{\mathrm{x}}$ are negligible. The results of our study are hence limited to cases of lightning events over rather clean regions; however, in cases in which a significant fraction of $\mathrm{NO}_{\mathrm{x}}$ originates from other sources, the discrimination and quantification of $\mathrm{LNO}_{\mathrm{x}}$ is difficult in any case, also by other methods.

In Beirle et al. (2006), an approach analogous to Eq. (12) was applied for the transformation of $\mathrm{S}^{\mathrm{LNO}_{2}}$ into $\mathrm{V}^{\mathrm{LNO}}$, using literature values for the $\mathrm{NO}_{\mathrm{x}}$ profile (Pickering et al., 1998; Fehr et al., 2004) and partitioning (Ridley et al., 1996) as well as for the box-AMFs (Hild et al., 2002) under cumulonimbus cloud conditions. The resulting conversion factor (defined in Beirle et al., 2006, as $\mathrm{V}^{\mathrm{LNO}_{\mathrm{x}}} / \mathrm{S}^{\mathrm{LNO}_{2}}$, i.e. the inverse of $\mathrm{E}$ in $\mathrm{Eq}$. 12) of 4.0 (2.1-7.1) corresponds to $\mathrm{E}=0.25$ (0.14-0.48). It has to be noted, however, that this sensitivity was calculated from profiles $p_{i}, l_{i}$, and $a_{i}$ that (a) are averages, i.e. do not reflect the high variability of meteorological and (photo-) chemical conditions within a mesoscale convective system (MCS), and (b) have been taken from different literature sources and for different thunderstorms, thus are inevitably inconsistent with respect to meteorologi$\mathrm{cal} / \mathrm{chemical}$ conditions, in particular trace gas profiles, cloud top height and -thickness.

Here we use a cloud resolving model, described in Sect. 2.2, in combination with a Monte-Carlo radiative transfer model (see Sect. 2.3) to: (a) calculate box-AMFs $a_{i}$ for thunderstorm simulations, (b) calculate sensitivities $\mathrm{E}$ and hence (c) derive $\mathrm{S}^{\mathrm{LNO}_{2}}$ (i.e., synthetic satellite measurements) for a variety of thunderstorm scenarios consistently (Sect. 2.4).

\subsection{Cloud resolving modelling: CSRMC}

The cloud system resolving model including chemistry (CSRMC) is based on a prototype version of the Weather Research and Forecasting (WRF) model (Skamarock et al., 2001) and is described in detail in Salzmann et al. (2008). It includes a simple flash rate parameterization based on Price 
and Rind (1992) which is tuned to approximately reproduce observed flash numbers in the TOGA COARE/CEPEX region. The partitioning between intra-cloud (IC) and cloud-toground (CG) flash rates is diagnosed using an empirical relationship (Price and Rind, 1993) between $\mathrm{Z}=\mathrm{N}_{\mathrm{IC}} / \mathrm{N}_{\mathrm{CG}}$ and the cold cloud height (defined as the vertical distance between the $0^{\circ} \mathrm{C}$ isotherm and cloud top). In the present study, results from the LTN3D run of Salzmann et al. (2008) are analyzed, in which $Z=10.43$. The vertical distributions of IC and CG flashes follow DeCaria et al. (2000, 2005), i.e. CG flash segments are assumed to have a Gaussian distribution and IC segments are assumed to have a bimodal distribution corresponding to a superposition of two Gaussian distributions. CG and IC flashes are assumed to produce $10 \times 10^{25}$ and $5 \times 10^{25} \mathrm{NO}$ molecules per flash, respectively. Flash rates and lightning NO production are calculated separately for each updraft core and for each anvil. Cores and anvils are identified as described in Salzmann et al. (2008). CG flashes are horizontally placed at the location of the maximum vertical updraft, which could lead to an over-estimate of $\mathrm{NO}_{\mathrm{x}}$ transported to the upper troposphere (see the discussion in Sect. 4.1 below).

A "background" $\mathrm{CH}_{4}-\mathrm{CO}-\mathrm{HO}_{\mathrm{x}}-\mathrm{NO}_{\mathrm{x}}$ tropospheric chemistry mechanism with additional reactions involving PAN (peroxy acetyl nitrate, $\mathrm{CH}_{3} \mathrm{C}(\mathrm{O}) \mathrm{O}_{2} \mathrm{NO}_{2}$ ), and loss reactions of acetone $\left(\mathrm{CH}_{3} \mathrm{COCH}_{3}\right)$ which is based on the mechanism from MATCH-MPIC (von Kuhlmann et al., 2003) has been used for simulating the influences of deep convection and lightning on chemistry in the TOGA COARE/CEPEX region.

\subsection{Radiative transfer modelling: the Monte-Carlo Model McArtim}

The Monte Carlo (MC) radiative transfer model (RTM) McArtim has been developed at the Institut für Umweltphysik (IUP), Universität Heidelberg, in recent years (Deutschmann, 2009). It is a further development of the RTM TRACY-II (Deutschmann and Wagner, 2006) that has been validated in a comparison study involving several RTM codes (Wagner et al., 2007).

MC is a well suited approach to model radiative transfer, in particular for a cloudy atmosphere. For given atmospheric conditions, i.e. profiles of temperature, pressure, and optical extinction coefficients from clouds and/or aerosols, McArtim generates a light path ensemble in a backward Monte-Carlo mode (Marchuk et al., 1980). From the resulting light path ensemble, in addition to radiances also box-AMFs can be derived (Wagner et al., 2007; Deutschmann, 2009) that are evaluated in this study.
2.4 Sensitivities and synthetic satellite SCDs for the TOGA-COARE lightning simulation

The CSRMC run in Salzmann et al. (2008) spans one week of a 3-D simulation of meteorology and (photo-) chemistry for thunderstorms in the Pacific, with output every $30 \mathrm{~min}$, and covers an area of $278 \times 278 \mathrm{~km}^{2}$ with $2 \mathrm{~km}$ spatial resolution in the horizontal and $500 \mathrm{~m}$ in the vertical. In this study, we consider the profiles from ground to $20 \mathrm{~km}$ altitude. In the following, we use the term "output time-step" (OTS) to denote the entity of data at a given output time-step, whereas "scene" denotes the entity of profiles and columns for a single $2 \times 2 \mathrm{~km}^{2}$ pixel.

For our analysis, we skip the night-time output time-steps (no photochemistry), and remove 10 pixels on each side in order to avoid boundary effects (instead of 8 pixels as in Salzmann et al., 2008). This leaves 138 OTSs with $119 \times 119$ pixels of $2 \times 2 \mathrm{~km}^{2}$ each, in total about 2 million scenes. For each of these scenes, a synthetic satellite observation is calculated:

First, the hydrometeor mixing ratios from the cloud resolving model are used to calculate visible extinction coefficients. Here we use the parameterization given in Platt (1997) (see page 2090, Eq. 28 therein):

$\sigma=\mathrm{j} \cdot \mathrm{W}^{\mathrm{k}}$

where $\mathrm{W}$ is the ice/water content, $\sigma$ is the extinction coefficient, and experimental values for the parameters $\mathrm{j}$ and $\mathrm{k}$ are given in Table 8 in Platt (1997) as 9.27 and 0.68, respectively. This parameterization has the significant advantage that it directly relates the liquid water content to the extinction coefficient, without the need of an effective radius. The resulting cloud optical thickness (COT) reaches about 120 at its maximum. Note that the experimental values in Platt (1997) are given for cirrus and frontal ice clouds. However, the resulting COTs are reasonable. In addition, our results are robust with respect to modifications of the extinction coefficients (see Sect. 4.1).

Second, the extinction coefficients are fed into the MCRTM McArtim to calculate box-AMFs $a_{i}$ for the respective scene, assuming horizontally homogenous clouds, and assuming that the scene is not affected by neighbouring scenes (independent pixel approximation, IPA).

The RTM is run assuming the cloud droplets having a single scattering albedo of 1 and a Henyey-Greenstein phase function with an asymmetry parameter of 0.85 . Ground albedo was set to $5 \%$, and calculations are performed for a solar zenith angle (SZA) of $20^{\circ}$. The wavelength is set to $440 \mathrm{~nm}$, matching the spectral fitting window of $\mathrm{NO}_{2}$ retrievals.

Third, tropospheric VCDs of $\mathrm{LNO}_{\mathrm{x}}$ are estimated: For this, the remaining stratospheric $(<20 \mathrm{~km})$ as well as the tropospheric background $\mathrm{NO}_{\mathrm{x}}$ columns have to be removed. This is done by subtracting a reference $\mathrm{NO}_{\mathrm{x}}$ profile that is estimated as the mean of the 1416 scenes $(1 \%$ of all scenes per OTS) with the lowest $\mathrm{NO}_{\mathrm{x}} \mathrm{VCD}$ for each OTS. The estimated 

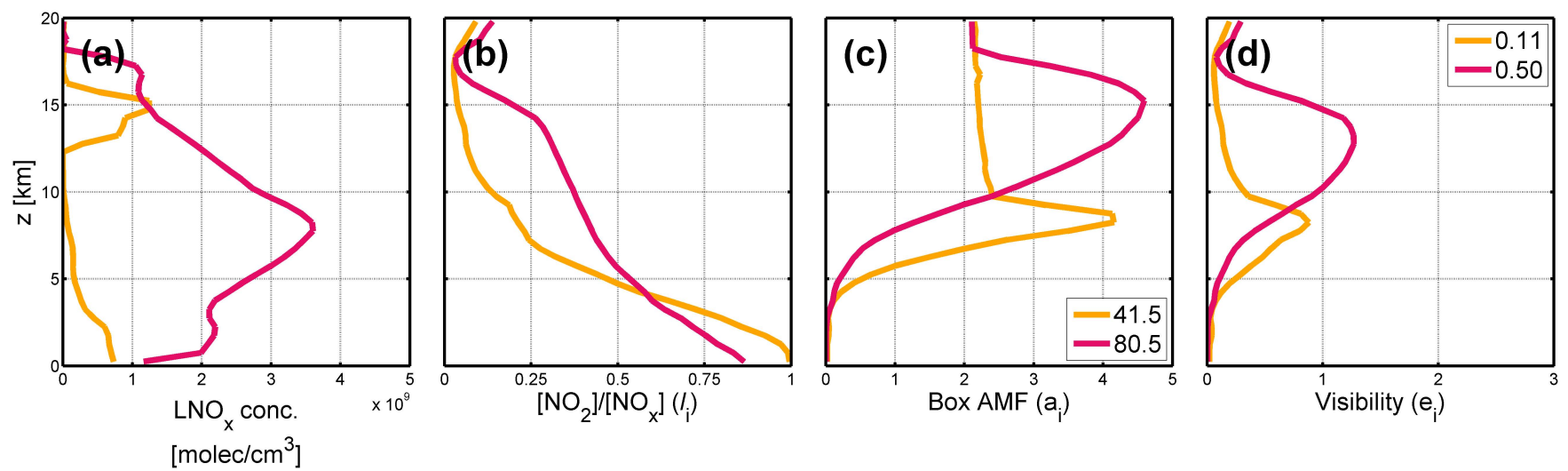

Fig. 1. Two illustrative examples from the simulation. The first (orange) represents a typical "C-shape" profile. The second (red) reflects a high $\mathrm{LNO}_{\mathrm{x}}$ column in the core region. (a) Profiles of $\mathrm{LNO}_{\mathrm{x}}$ concentration. (b) $\mathrm{NO}_{2} / \mathrm{NO}_{\mathrm{x}}$ ratio $\left(l_{i}\right)$. (c) box-AMFs $\left(a_{i}\right)$ as calculated by the McArtim RTM. The numbers in the legend are the respective cloud optical depth. (d) Resulting Visibility $\left(e_{i}\right)$. The resulting Sensitivities E are given in the legend in (d).

background columns (i.e. the integrated reference $\mathrm{NO}_{\mathrm{x}}$ profiles) range from $2.5-3.8 \times 10^{14}$ moelc $/ \mathrm{cm}^{2}$. From the background corrected $\mathrm{NO}_{\mathrm{x}}$ profiles, background corrected $\mathrm{NO}_{2}$ profiles are calculated using the actual $\mathrm{NO}_{2} / \mathrm{NO}_{\mathrm{x}}$ ratio for each layer. Hereafter, all $\mathrm{NO}_{\mathrm{x}} / \mathrm{NO}_{2}$ profiles/columns are corrected for this background. These corrected profiles/columns contain the lightning produced $\mathrm{NO}_{\mathrm{x}} / \mathrm{NO}_{2}$, and are thus denoted with the superscript ${ }^{\mathrm{L}}$ in the following.

Finally, visibilities $e_{i}$ (Eq. 6) and sensitivities E (Eq. 13) are calculated, using the $\mathrm{NO}_{2} / \mathrm{NO}_{\mathrm{x}}$ ratio $\left(l_{i}\right)$ from the CSRMC and the RTM box-AMFs $\left(a_{i}\right)$. The synthetic SCDs of $\mathrm{LNO}_{2}$ are calculated according to Eq. (12).

\section{Results}

\subsection{Individual scenes}

For 2 million scenes from the CSRMC model run, box-AMFs and sensitivities are calculated. For the further analysis, we only consider (a) output time steps (OTSs) with more than 50 flashes, resulting in 50 OTSs, and for each of these OTS (b) scenes with $\mathrm{V}^{\mathrm{LNO}_{\mathrm{x}}}>10^{14} \mathrm{molec} / \mathrm{cm}^{2}$, to restrict our study to cases that actually contain $\mathrm{LNO}_{\mathrm{x}}$ (see Appendix A, Eq. A4), resulting in 167820 scenes. For the calculation of spatial means, however, all scenes are considered (see below). Please recall that in the following (if not labelled differently), "sensitivity" and "E" refer to the sensitivity for lightning $\mathrm{NO}_{\mathrm{x}}$ according to (Eqs. 12 and 13), even if the superscript ${ }^{\mathrm{L}}$ is omitted.

Figure 1 shows the $\mathrm{LNO}_{\mathrm{x}}$ profile, the respective $\mathrm{NO}_{\mathrm{x}}$ partitioning $l_{i}$, the box-AMFs $a_{i}$, and the visibility $e_{i}$, for two selected, illustrative sample scenes.

The first selected example (orange) shows a typical " $\mathrm{C}$ shape" $\mathrm{LNO}_{\mathrm{x}}$ profile (a) with a pronounced peak at $\sim 15 \mathrm{~km}$ and almost no $\mathrm{NO}_{\mathrm{x}}$ in the middle troposphere. The $\mathrm{NO}_{\mathrm{x}}$ at the ground (b) is nearly completely present as $\mathrm{NO}_{2}$, while at $15 \mathrm{~km}$ it is dominated by NO due to the high actinic flux and the low temperatures. The box-AMFs (c) above $10 \mathrm{~km}$ are slightly higher than 2 , similar to the stratospheric AMF, but jump to a value of 4 at $9 \mathrm{~km}$ due to an optically thick cloud (COT=41.5). Below, $a_{i}$ decreases, and reaches values $<0.1$ for altitudes $<4 \mathrm{~km}$ and $<0.02$ for the lowest layer. The box-AMF profile is generally similar to the box-AMF presented in Hild et al. (2002). The resulting visibility is low (0.02) at the ground (due to the low $a_{i}$ ), peaks at $8 \mathrm{~km}$, reaching $\sim 0.9$, and is low (min. 0.06 ) again in the UT due to the low $\mathrm{NO}_{2} / \mathrm{NO}_{\mathrm{x}}$ ratio. The resulting sensitivity is rather low $(\mathrm{E}=0.11)$, since the $\mathrm{LNO}_{\mathrm{x}}$ is $\mathrm{C}$-shaped, i.e., has its peaks where the visibility is small.

The second example (red) displays a case of a very high $\mathrm{LNO}_{\mathrm{x}}$ column shortly after the release of fresh NO from lightning: the $\mathrm{NO}_{2} / \mathrm{NO}_{\mathrm{x}}$ (b) at the ground has not yet reached photo stationary state. The $\mathrm{LNO}_{\mathrm{x}}$ concentration (a) shows no C-shape, but instead is high throughout the troposphere, peaking at $8 \mathrm{~km}$. The box-AMFs (c) result from a very high $(\mathrm{CTH}=17.8 \mathrm{~km}$, where Cloud Top Height is defined as the highest altitude where hydrometeor mass mixing ratios exceed $0.01 \mathrm{~g} / \mathrm{kg}$ ), optically thick $(\mathrm{COT}=80.5)$ cumulonimbus cloud. As in the first example, the visibility is low at the ground as well as at the tropopause, but peaks at $13 \mathrm{~km}$ (i.e., $2 \mathrm{~km}$ below the peak in box-AMFs). As a result of the high $\mathrm{LNO}_{\mathrm{x}}$ throughout the troposphere, the resulting sensitivity is much higher $(\mathrm{E}=0.50)$ than in the first case.

After discussing these two selected examples that illustrate some general features of $p_{i}, l_{i}, a_{i}$, and $e_{i}$, we now analyse mean conditions over the complete simulated data. To investigate possible systematic differences, the scenes have been grouped into five regimes that are defined as follows (the listed colours are used in all following plots to identify the regimes): 

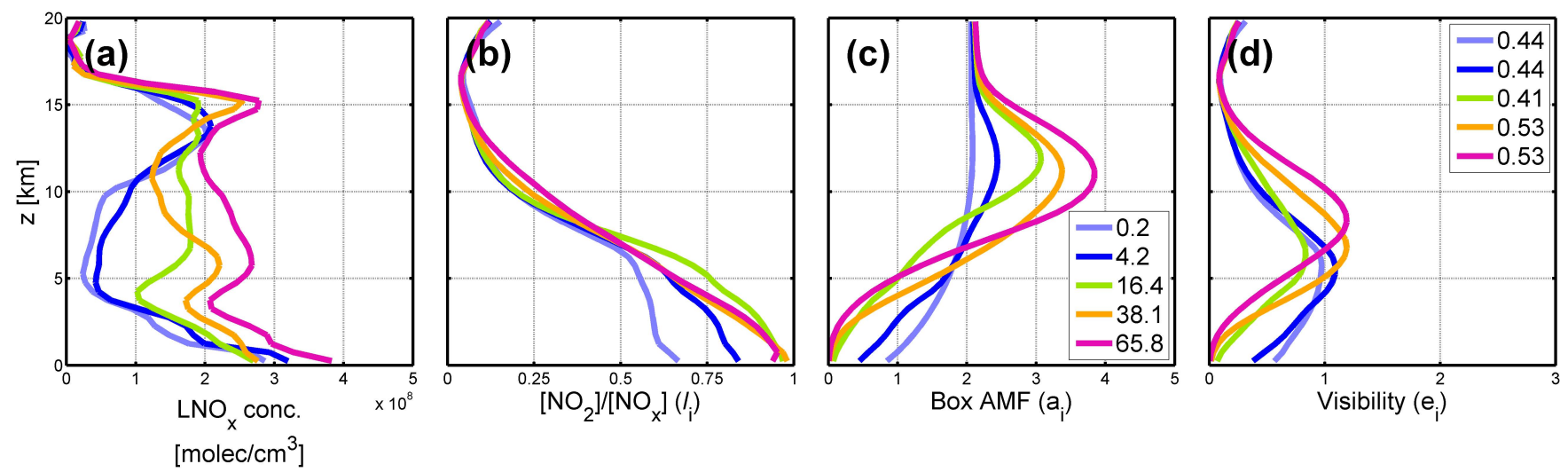

Fig. 2. Mean profiles for the scenes classified in different regimes (I-V) according to COT (see text). Panels as in Fig. 1. Note the change of scale in (a) compared to Fig. 1. "Mean" $l_{i}$ is defined as mean $\left(\left[\mathrm{NO}_{2}\right]\right) /$ mean $\left(\left[\mathrm{NO}_{\mathrm{x}}\right]\right)\left(\right.$ the $\mathrm{NO}_{2}$ and $\mathrm{NO}_{\mathrm{x}}$ concentrations in layer $\mathrm{i}$ are averaged across all scenes of the respective regime).

- Regime I (light blue): defined by COT $<1$.

- Regime II (blue): defined by $1<\mathrm{COT}<10$.

- Regime III (green): defined by $10<\mathrm{COT}<30$.

- Regime IV (orange): defined by $30<\mathrm{COT}<50$.

- Regime V (red): defined by $50<$ COT.

This classification serves as indicator of the different regimes of a deep convective system: Regime I summarizes cloud free conditions. The outflow will mostly fall in regime II, whereas anvils will be classified as regime III or IV. The cores are predominantly classified as regime $\mathrm{V}$ due to the high COT.

Note that we also applied a finer classification, using vertical wind speeds to separate up- and downdraft regions. However, we found no systematic differences in the sensitivities for scenes with up- or downdraft conditions (the correlation coefficient of sensitivities $\mathrm{E}$ and vertical wind speeds $\mathrm{w}$ is $R=-0.06$ ), and thus classify the regimes simply by COT in this study.

Figure 2 shows the mean profiles for the different regimes. The general features are similar to the examples shown in Fig. 1, but reveal some systematic differences for the five regimes: The $\mathrm{LNO}_{\mathrm{x}}$ concentrations (a) show a peak at the ground and at the tropopause (note the change in scale by a factor of 10 compared to Fig. 1a); however, the profiles of regimes I\&II have low values in the middle troposphere, whereas the concentration is high throughout the troposphere for regime $\mathrm{V}$. The $\mathrm{NO}_{\mathrm{x}}$ partitioning (b) is close to 1 at the ground (but only 0.7 for cloud free scenes due to the higher photolysis) and decreases to $\sim 0.05$ at $15 \mathrm{~km}$. The box-AMFs (c) are low at the ground, peaking in the upper troposphere (except cloud free), reaching values up to 4 for regime $\mathrm{V}$, and approaching stratospheric box-AMFs at the tropopause. It has to be noted that the smoothness of the box-AMFs is a result of the averaging process, while individual scenes show sharp discontinuities at the cloud top (compare Fig. 1c). The resulting visibility (d) again shows the "inverted C-shape", peaking in the middle troposphere and having low values at the ground as well as at the tropopause. For regimes I and II (i.e. COT $<10$ ), visibility at the ground is still quite substantial $(\sim 0.5)$. Note that box-AMFs differ significantly for the five regimes, increasing from 2 (I) to 4 (V) at about $10 \mathrm{~km}$, and decreasing from $1(\mathrm{I})$ to almost $0(\mathrm{~V})$ at the ground. The visibilities, on the other hand, vary much less from regime to regime.

The resulting mean sensitivities are also similar for the five regimes and range from 0.44 (regimes I and II) over 0.41 (regime III) to 0.53 (regimes IV and V). Thus, scenes of medium COT, as occurring in the anvil, show the lowest sensitivity, whereas E is higher both for regimes I and II (due to the "transparency" of the cloud) and for regimes IV and V (due to the rather smooth $\mathrm{LNO}_{\mathrm{x}}$ profile that is high throughout the troposphere, and the higher box-AMFs).

To also illustrate the extremes of the simulated profiles within each regime, Figs. 3 and 4 show the scenes of lowest and highest sensitivity for the five regimes, respectively (for these plots, we ignored scenes where the backgroundcorrected profiles of $\mathrm{NO}_{\mathrm{x}}$ become negative).

Figures $3 \mathrm{a}$ and $4 \mathrm{a}$ in particular illustrate the high variability of $\mathrm{LNO}_{\mathrm{x}}$ profiles. The resulting visibilities (Figs. $3 \mathrm{~d}$ and $4 d$ ), however, all show the same general pattern of a minimum at the tropopause, a maximum in the free troposphere between 5 and $10 \mathrm{~km}$ (except for being $\sim 13 \mathrm{~km}$ for regime IV in $4 \mathrm{~d}$ ), and a second minimum at the ground.

As a consequence, highest sensitivities (Fig. 3) are generally found for $\mathrm{LNO}_{\mathrm{x}}$ profiles with a substantial fraction in the middle troposphere, where visibility is highest and can reach values of up to 3 for regime V. Cases of lowest sensitivity (Fig. 4), on the other hand, generally show no $\mathrm{LNO}_{\mathrm{x}}$ between 5 and $10 \mathrm{~km}$. The minimum scene of regime IV 

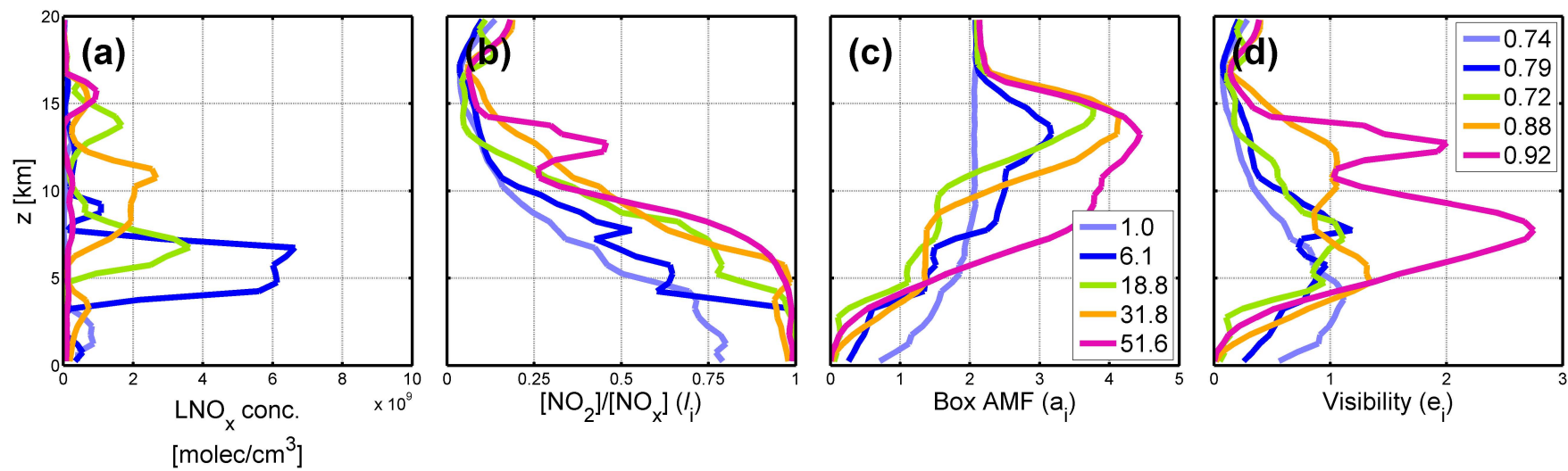

Fig. 3. Sample profiles of the cases with highest sensitivity for the five regimes. Colours as in Fig. 2. Note the change of scale in (a).
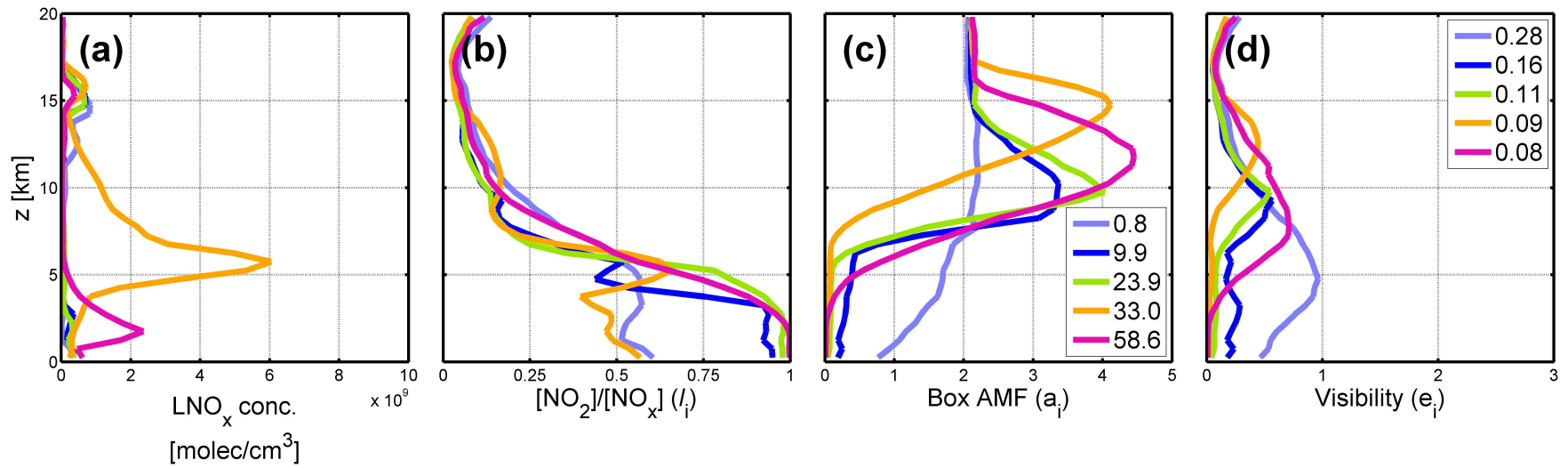

Fig. 4. Sample profiles of the cases with lowest sensitivity for the five regimes. Colours as in Fig. 2.

is exceptional in this case: Here we have fresh lightning production (note that only $50 \%$ of the $\mathrm{NO}_{\mathrm{x}}$ is $\mathrm{NO}_{2}$ at the ground!) that is shielded by a high cloud $(\mathrm{CTH}=17.3 \mathrm{~km})$. Thus, low sensitivities occur for $\mathrm{LNO}_{\mathrm{x}}$ below or above the cloud, while high sensitivities are observed for $\mathrm{LNO}_{\mathrm{x}}$ within the cloud.

These extreme cases illustrate under which conditions $\mathrm{LNO}_{\mathrm{x}}$ is highly visible or almost invisible for nadir viewing satellites. However, these events are very rare in the complete simulation. The resulting sensitivity of all scenes has a mean of 0.41 , a median of 0.39 , and a standard deviation of 0.15 . Figure 5 displays the frequency distribution of the modelled sensitivities. Hence, despite the high variability of meteorological and chemical conditions within the thunderstorm simulation, the resulting sensitivities vary less than we had initially anticipated. Figure 6 shows scatterplots of the sensitivity against the respective COT (left) and $\mathrm{V}^{\mathrm{LNO}_{\mathrm{x}}}$ (right) for all considered scenes. The correlation coefficients are $R=-0.27$ and $R=-0.17$, respectively. If sensitivities are averaged for the different regimes separately, we find means of $0.45,0.42,0.28,0.32$, and 0.40 for regimes $\mathrm{I}-\mathrm{V}$, respectively. Note that these mean sensitivities differ from the numbers

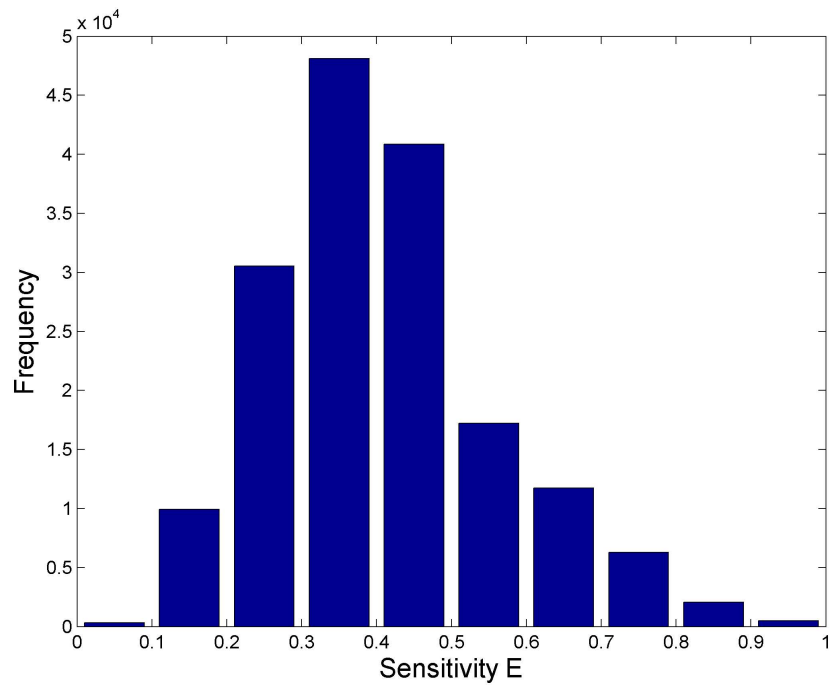

Fig. 5. Frequency distribution of the resulting sensitivities. $81 \%$ of all individual sensitivities are between 0.2 and 0.6. 

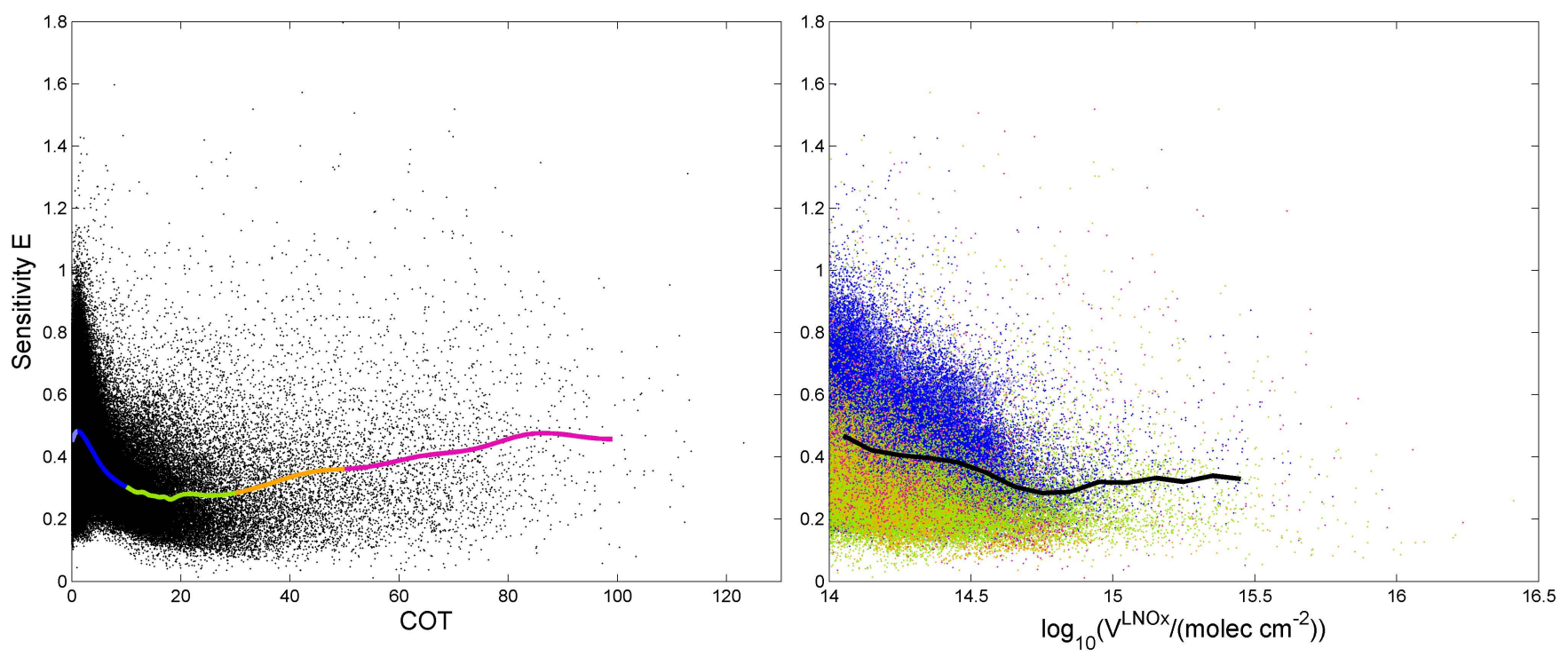

Fig. 6. Scatterplot of sensitivity $\mathrm{E}$ versus cloud optical thickness (left) and $\mathrm{V}^{\mathrm{LNO}_{\mathrm{x}}}$ (right) for all analyzed scenes. Colour indicates the different regimes (colours as in Fig. 2). The respective correlation coefficients are $R=-0.27$ and $R=-0.17$. The curves show mean sensitivities for (left) binned COT $(\Delta \mathrm{COT}=1$ for $\mathrm{COT}<=20$ and 10 above $)$ and (right) binned $\mathrm{V}^{\mathrm{LNO}_{\mathrm{x}}}\left(\Delta \log _{10}\left(\mathrm{~V}^{\mathrm{LNO}} \mathrm{x}_{\mathrm{x}}\right)=0.1\right)$.

given in Fig. 2, since here we directly give the average of the individual sensitivities, while in Fig. 2 the "mean" sensitivities are calculated from the averaged profiles, partitioning, and box-AMFs. As in Fig. 2, but more obvious, scenes with medium COT (regime III), as well as scenes with medium $\mathrm{V}^{\mathrm{LNO}_{\mathrm{x}}}$, have the lowest sensitivity.

Besides discussing typical, mean, and extreme profiles, the model data also allows us to study the spatial patterns of the resulting $\mathrm{V}^{\mathrm{LNO}_{\mathrm{x}}}$ and $\mathrm{S}^{\mathrm{LNO}_{2}}$ columns and the respective sensitivities at a given OTS. Figure 7 displays the spatial distribution of COT and regime classification for two selected OTSs that have low and high overall sensitivity. The left column displays the OTS from 19 December 1992, at 22:30 UTC. This is an early stage of the simulation. In the northern part, a strong, quite homogenous convective system can be seen. In the right column, from 23 December 1992, 21:30 UTC, the situation is much less homogenous. There are several convective cells distributed over the model domain. The respective model flash counts within the last $30 \mathrm{~min}$ are 304 and 83 .

Figure 8 displays maps of $\mathrm{V}^{\mathrm{LNO}_{x}}, \mathrm{~S}^{\mathrm{LNO}_{2}}$, and $\mathrm{E}$, for the respective OTS. In both cases, the resulting sensitivities show spatial structures that relate to Fig. 7. Again, a tendency towards lower sensitivities for regime III is noted. However, the differences between the mean sensitivities for the different regimes are much smaller than the spatial variability seen in Fig. 8. Thus the resulting spatial patterns of $\mathrm{E}$ are mainly a consequence of some horizontally smooth patterns for $p_{i}$, $l_{i}$, and $a_{i}$, and can only partly be summarized by a simple dependency on regime classification, i.e., on COT.

\subsection{Total sensitivity (spatial mean)}

In practice, a quantitative estimate of $(\mathrm{L}) \mathrm{NO}_{\mathrm{x}}$ using satellite measurements is typically based on a spatial mean, rather than on single columns, to account for uncertainties in flash locations and transport. We calculate the spatial mean sensitivity for each OTS (denoted as $\mathrm{E}_{\text {total }}$ hereafter) as

$\mathrm{E}_{\text {total }}:=\frac{\overline{\mathrm{SNO}_{2}}}{\overline{\mathrm{VLNO}_{\mathrm{x}}}}$

i.e. the spatially mean enhancement in the synthetic satellite observation in relation to the spatially mean release of $\mathrm{LNO}_{\mathrm{x}}$. Note that a spatial mean eliminates individual scenes of extreme high/low sensitivity if they contain no (or low) lightning $\mathrm{NO}_{\mathrm{x}}$. It is the aim of this study to provide the total sensitivity (Eq. 15) for use in future observational studies, where the produced $\mathrm{LNO}_{\mathrm{x}}$ can be estimated from measurements of mean (background corrected) $\mathrm{SCDs}$ of $\mathrm{NO}_{2}$, by applying $\mathrm{E}_{\text {total }}$.

The resulting sensitivities $\mathrm{E}_{\text {total }}$ for the sample OTS are 0.31 and 0.66 , respectively. The averaging of the total mean sensitivities over all OTSs results in $\mathrm{E}_{\text {total }}=0.46$ (standard deviation 0.09 ). This is slightly higher than the mean of the individual sensitivities (0.41) due to nonlinearities (Eq. 15) and due to the fact that scenes with $\mathrm{V}^{\mathrm{LNO}_{\mathrm{x}}}<10^{14} \mathrm{molec} / \mathrm{cm}^{2}$ are skipped in the average of individual sensitivities, but not in the calculation of $\mathrm{E}_{\text {total }}$. 

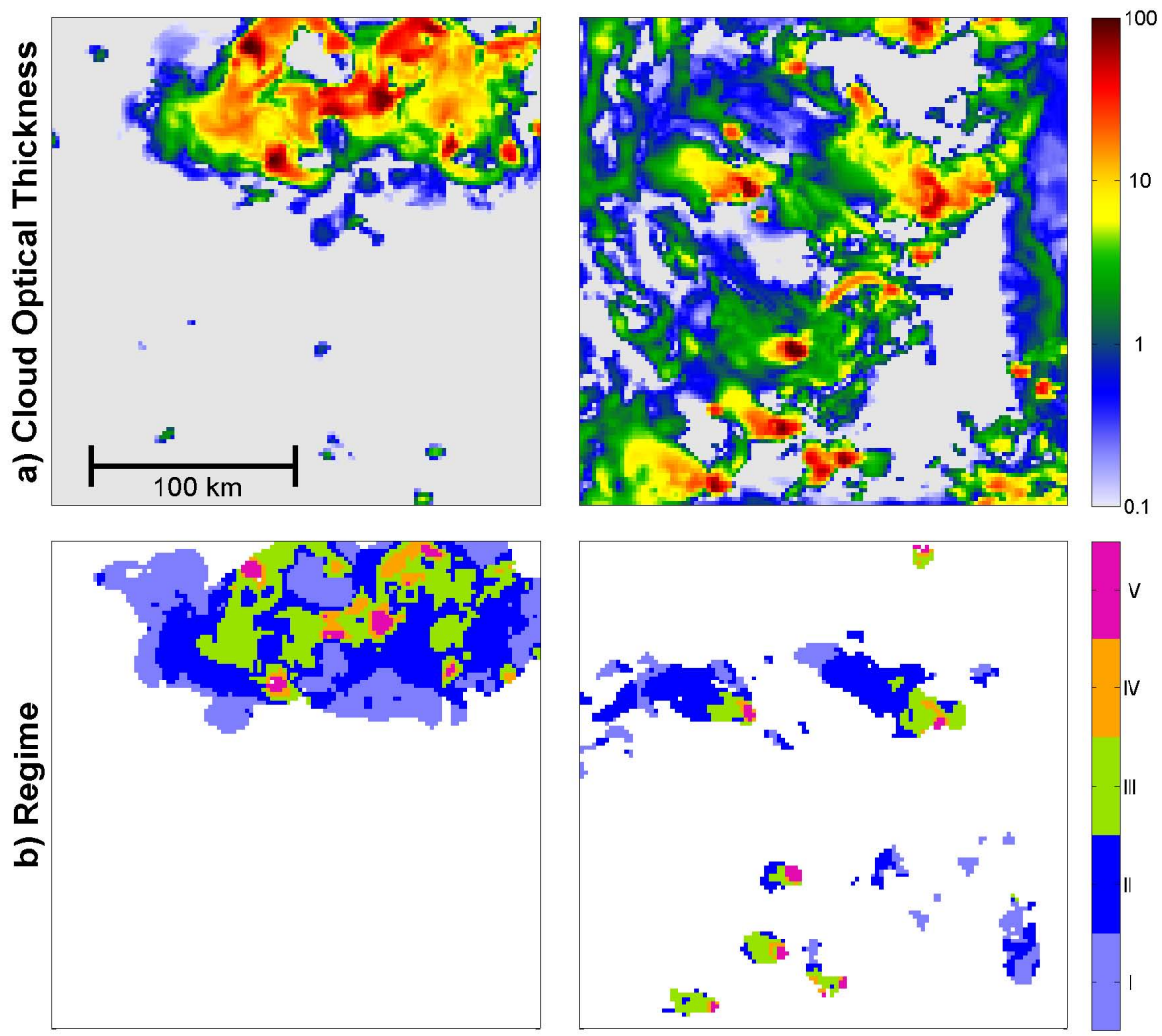

Fig. 7. Maps of (a) COT and (b) regime classification for two illustrative OTSs that represent a case of low sensitivity (left column, $\mathrm{E}_{\mathrm{total}}=0.31$ ), and high sensitivity (right column, $\mathrm{E}_{\text {total }}=0.66$ ), respectively. In (b), pixels with $\mathrm{V}^{\mathrm{LNO}_{\mathrm{x}}}<10^{14}$ molec/cm ${ }^{2}$ are masked out.

3.3 Impact of the spatial resolution of the satellite instrument

The $\mathrm{S}^{\mathrm{LNO}_{2}}$ shown in Fig. $8 \mathrm{~b}$ is the synthetic slant column, i.e. the column a nadir viewing satellite (with $2 \times 2 \mathrm{~km}^{2}$ spatial resolution) would actually "see". Note the high spatial gradients: due to the local release of high amounts of $\mathrm{LNO}_{\mathrm{x}}$, individual pixels show $\mathrm{S}^{\mathrm{LNO}_{2}}>5 \times 10^{15}$ above the background. Hence, studies of freshly produced $\mathrm{LNO}_{\mathrm{x}}$ from space will profit from improved spatial resolutions of future satellite instruments.

Current instruments have a coarser spatial resolution, e.g. $30 \times 30 \mathrm{~km}^{2}$ for SCIAMACHY in short integration time mode. Figure 9 shows the synthetic $\mathrm{S}^{\mathrm{LNO}_{2}}$ for this SCIAMACHY resolution, illustrating the loss of spatial information. Note that average $\mathrm{S}^{\mathrm{LNO}_{2}}$ are calculated as the mean of the pixels $\left(2 \times 2 \mathrm{~km}^{2}\right)$ within the $30 \times 30 \mathrm{~km}^{2}$ weighted by the respective intensities (clouded pixels are brighter and hence contribute more light to the detector measurement), as in real satellite observations. The resulting sensitivities have a mean of 0.41 and a standard deviation of 0.13 , comparable to the values for the original model resolution (see Sect. 3.1).

Total sensitivities based on the sensitivities for reduced spatial resolution are 0.31 and 0.71 for the OTSs shown in
Fig. 9, i.e. slightly higher than for the original resolution for the second example. This increase is mainly caused by the two pixels with high sensitivity (Fig. 9c) that result from the intensity weighted average of $\mathrm{S}^{\mathrm{LNO}_{2}}$. At this OTS, a small region with high $\mathrm{S}^{\mathrm{LNO}_{2}}$ dominates the $30 \times 30 \mathrm{~km}^{2}$ pixel since it coincides with high COT. Note, however, in general $\mathrm{S}^{\mathrm{LNO}_{2}}$, as $\mathrm{V}^{\mathrm{LNO}_{\mathrm{x}}}$, does not correlate with COT $(R=0.07$; compare also Fig. 6), i.e. this effect is not systematic. The frequency distributions of total sensitivities on SCIAMACHY resolution (mean 0.47, standard deviation 0.10) is close to the results on original resolution $(0.46 / 0.09)$. So the principal results of our study on mean sensitivities are not affected by the footprint of the satellite instrument. However, the loss of spatial information is evident.

\section{Discussion}

\subsection{Uncertainties}

The presented calculation of synthetic satellite measurements and sensitivities is based on model profiles of $\mathrm{NO}_{\mathrm{x}}$, $\mathrm{NO}_{2}$, and clouds, combined with radiative transfer calculations. Here we discuss the uncertainties due to the assumptions made and methods applied in this study. 

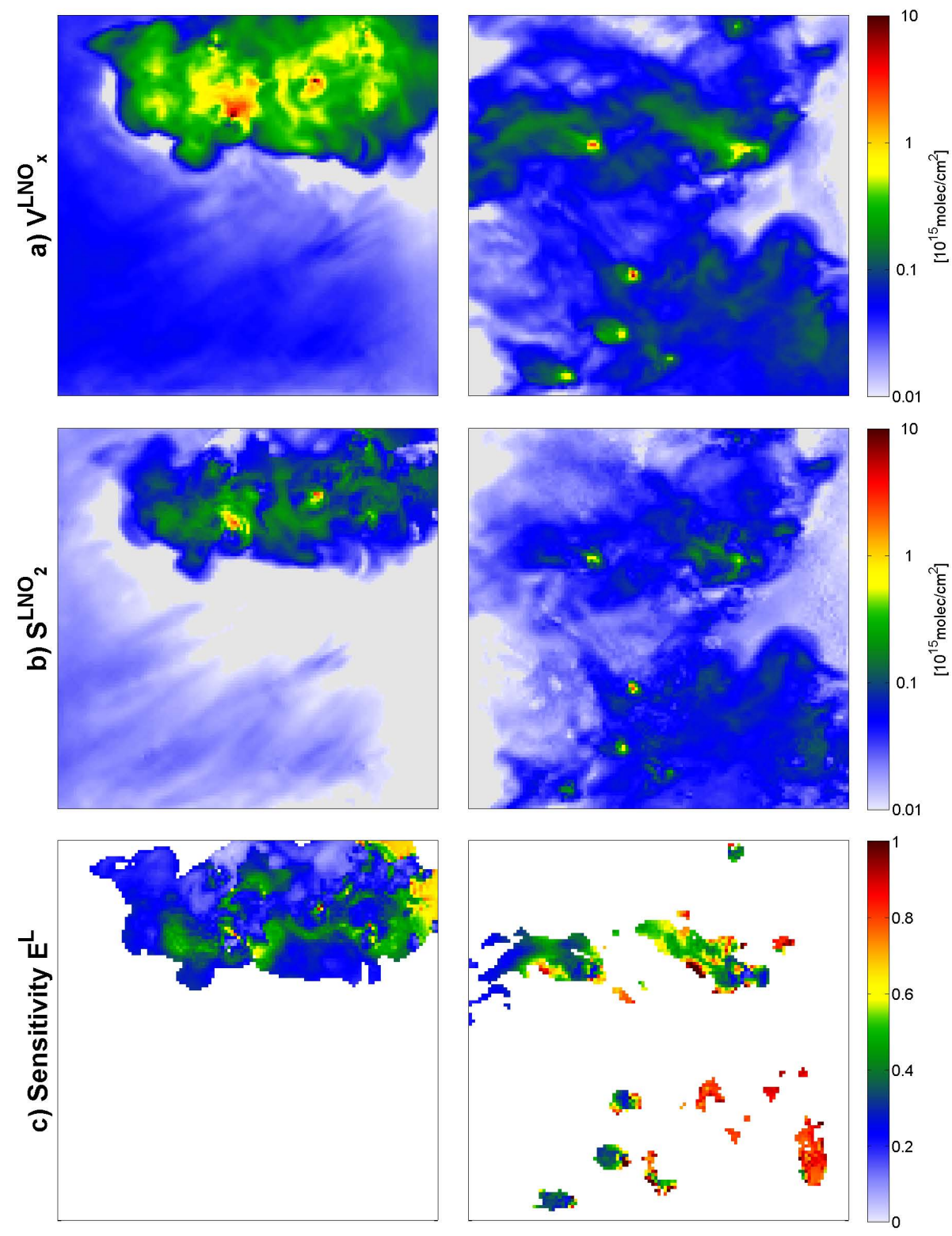

Fig. 8. Maps of (a) $\mathrm{V}^{\mathrm{LNO}_{\mathrm{x}}}$, (b) $\mathrm{S}^{\mathrm{LNO}_{2}}$, and (c) sensitivity $\mathrm{E}^{L}$, for the two OTSs shown in Fig. 7. In (c), pixels with $\mathrm{V}^{\mathrm{LNO}}<10^{14}$ molec/cm ${ }^{2}$ are masked out.

\subsubsection{Uncertainties of the model}

Cloud system resolving models (CSRMs) can explicitly resolve an important part of the cloud system dynamics, while cloud microphysical processes are parameterized. The present model is the first of its kind in that it includes chemistry in a cloud system resolving model framework in which so-called large scale forcing terms are added to the equation for water vapour and temperature, thus largely constraining the simulations to reproduce the observed total precipitation.
The meteorological setup applied in the present study has been evaluated in Salzmann et al. $(2004,2008)$ based on observations in the TOGA COARE campaign (Webster and Lukas, 1992), suggesting that the model performance is comparable to that found in other TOGA COARE CSRM studies. The chemistry part of the CSRMC has been extensively evaluated in Salzmann et al. (2008) based on observations from adjacent regions, showing reasonably good agreement for key compounds (see electronic supplement to Salzmann et al., 2008, http://www.atmos-chem-phys.net/8/2741/2008/ acp-8-2741-2008-supplement.pdf, for details). 

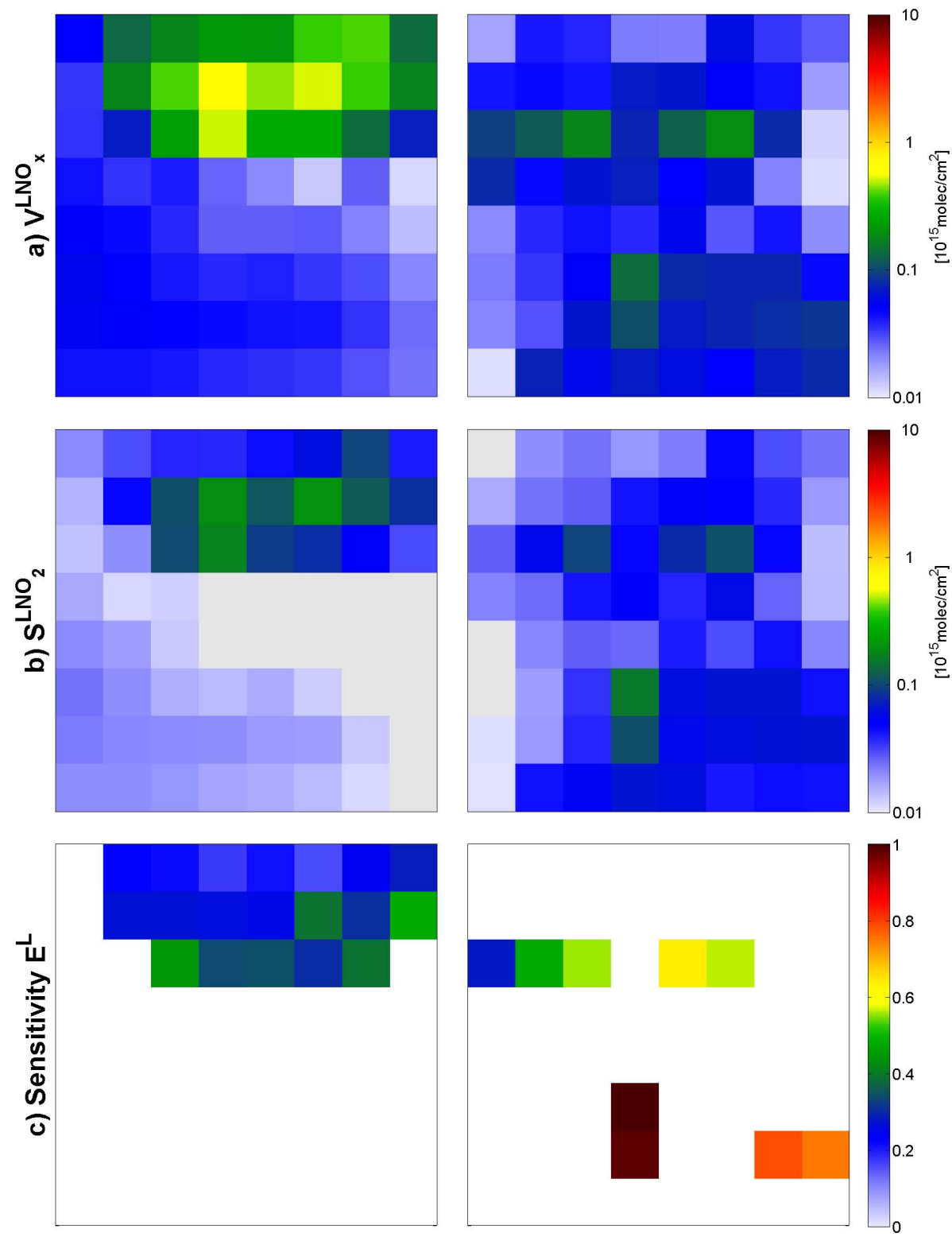

Fig. 9. As Fig. 8, but for reduced spatial resolution $\left(30 \times 30 \mathrm{~km}^{2}\right)$. Note that the spatial mean $\mathrm{S}^{\mathrm{LNO}_{2}}$ has been weighted by the respective intensity of the single scenes to simulate the satellite measurement.

We have tuned the lightning parameterisation to approximately yield observed flash numbers in the TOGA COARE/CEPEX region. Large uncertainty exists, however, with respect to the IC/CG ratio, which can not be inferred with confidence from the lightning observations during TOGA COARE. The simulated IC/CG ratio (10.43) is in line with observations of average tropical IC/CG ratios by Pierce et al. (1970). However, recent studies report on lower IC/CG ratios (see Table 9 in Schumann and Huntrieser, 2007) of about 3 rather than 10. On the other hand, Table 19 in Schumann and Huntrieser (2007) indicates that IC flashes are probably as effective with respect to $\mathrm{NO}_{\mathrm{x}}$ production as CG flashes. Those two effects are in opposite direction (we might have overestimated the number of IC flashes, but underestimated their $\mathrm{NO}_{\mathrm{x}}$ production efficiency) and partly compensate each other. However, direct measurements are still rare, and storm-to-storm variability is probably quite high.

The horizontal and vertical placement of IC and CG flashes introduces an additional uncertainty. CG flashes are horizontally placed at the location of the maximum vertical velocity. This choice is consistent with Ray et al. (1987), who found, based on dual Doppler radar and very high frequency lightning observations, that in a multi-cell storm, lightning tended to coincide with the reflectivity and updraft core. It could, nevertheless, potentially lead to a small over-estimate 
Table 1. Effect of modifications of RTM settings on the resulting sensitivity for the first OTS shown in Fig. 7 (left). The resulting sensitivity for standard settings is 0.306 .

\begin{tabular}{lllllllllll}
\hline & \multicolumn{2}{c}{$\mathrm{SZA}=$} & \multicolumn{2}{c}{$\mathrm{SSA}=$} & \multicolumn{2}{c}{$\mathrm{g}=$} & \multicolumn{2}{c}{ Ground albedo= } & Extinction coefficient \\
\hline Modification & $40^{\circ}$ & $60^{\circ}$ & 0.9999 & 0.999 & 0.8 & 0.9 & $0 \%$ & $10 \%$ & $* 0.5$ & $* 2$ \\
Sensitivity & 0.313 & 0.334 & 0.305 & 0.301 & 0.287 & 0.339 & 0.236 & 0.357 & 0.365 & 0.266 \\
Relative change & $+2 \%$ & $+9 \%$ & $-0 \%$ & $-2 \%$ & $-6 \%$ & $+11 \%$ & $-23 \%$ & $+17 \%$ & $+19 \%$ & $-13 \%$ \\
\hline
\end{tabular}

of the upward transport of lightning $\mathrm{NO}_{\mathrm{x}}$, if lightning occurs predominantly downwind of the updraft cores, as reported in Dye et al. (2000) for a continental thunderstorm over the US.

While the vertical placement is based on observations of lightning channel segments as in DeCaria et al. (2000) (see above), we do not explicitly take into account branching for placing flashes horizontally. This could result in an overestimate of local NO maxima. On the other hand, the flash rates and NO production are calculated for each $8 \mathrm{~s}$ model time step, which introduces some artificial "smearing out" and a reduction of the local NO maxima. Finally, the simulated $\mathrm{NO} / \mathrm{NO}_{2}$ ratios depend on the number of $\mathrm{NO}$ molecules produced per flash, which is still rather uncertain. This effect is difficult to quantify, since multi-day 3-D sensitivity studies including chemistry are still computationally expensive.

It has to be noted, however, that despite the high variability of meteorological and lightning conditions within the model, including scenes with IC as well as CG flashes, the modelled sensitivities show rather low variability over all scenes; $81 \%$ of all sensitivities are between 0.2 and 0.6. We could not find a dependency of sensitivities on vertical wind speeds. In addition, if we shift the $\mathrm{NO}_{\mathrm{x}}$ and $\mathrm{NO}_{2}$ profiles vertically by one layer $(500 \mathrm{~m})$ either up or down, our results change by less than $5 \%$. Hence the impact of a possible systematic $\mathrm{LNO}_{\mathrm{x}}$ profile bias (due to inaccurate assumptions on IC and CG lightning properties as well as horizontal placement of flashes) on our results is likely to be small.

\subsubsection{Uncertainties of the radiative transfer calculations}

The Monte Carlo RTM McArtim, successor of TRACY-2, is a powerful, flexible program for the calculation of boxAMFs under various atmospheric conditions. The resulting radiances and box-AMFs have been validated (Wagner et al., 2007). At present, however, only 1-D cloud profiles can be considered. Future versions of McArtim will allow the definition of 3-D fields of scattering particles (Deutschmann, 2009).

We calculated box-AMFs using the independent pixel approximation (IPA). RTM is applied for 1-D cloud layers for each pixel separately, neglecting the horizontal photon fluxes between neighbouring pixels of different cloud properties. For the rather small pixels of $2 \times 2 \mathrm{~km}^{2}$ size, the limitations of the IPA may become an issue (Marchak et al., 1998). For instance, for the extreme case of a clouded scene with high COT surrounded by cloud free scenes, the cloud would scatter the sunlight out of the considered pixel, whereas in our calculation, assuming homogenous cloud layers, light also comes back from the surrounding pixels. Hence, a 3-D calculation would lead to a more effective shielding than in our analysis, and we overestimate the visibility below the cloud for such an extreme case. On the other hand, a cloud free pixel within clouded pixels would be influenced by scattered light coming from the surrounding pixels, that increases the visibility at the altitudes of the surrounding clouds. Hence, in such cases we underestimate the actual visibility. Things get even more complicated due to the slant irradiation (here: $\mathrm{SZA}=20^{\circ}$ ), which leads to shadowing effects and irradiation of the cloud flanks.

A quantification of these effects is rather difficult. The hydrometeor as well as the $\mathrm{NO}_{\mathrm{x}}$ profiles differ from pixel to pixel. Currently, 3-D clouds are not yet implemented in McArtim, and the computational effort of a full 3-D run over the complete model period would exceed the available computer power. Furthermore, photolysis rates calculated in the CSRMC also use the IPA and cannot be modified afterwards.

So the IPA may lead to a bias of our results, but its overall impact is probably of minor importance: First, the distribution of hydrometeors and $\mathrm{NO}_{\mathrm{x}}$ on the $2 \times 2 \mathrm{~km}^{2}$ resolution is in general rather smooth. Extreme jumps of COT or $\mathrm{NO}_{\mathrm{x}}$ from one pixel to another occur occasionally, but are exceptional. Second, the effects of the IPA can result both in an over- as well as an underestimation of visibilities, that at least partly cancel out each other. Finally, the change in photon paths for a real 3-D run would change the box-AMFs, as well as the photolysis rates, damping the net effect (in other words: more light through the cloud increases the box-AMF $a_{i}$ (enhancing visibilities $e_{i}$ ), but decreases the $\mathrm{NO}_{2} / \mathrm{NO}_{\mathrm{x}}$ ratio $l_{i}$ (decreasing visibilities $e_{i}$ ), and vice versa).

For the RTM runs, the following assumptions on viewing geometry and optical cloud properties have been made: solar zenith angle $(\mathrm{SZA})=20^{\circ}$, single scattering albedo $(\mathrm{SSA})=1$, asymmetry parameter $g=0.85$, ground albedo $=5 \%$, and extinction coefficients according to Eq. (14). To study the impact of these settings, we modified all parameters exemplarily for the first sample OTS with $E_{\text {total }}=0.31$. Table 1 lists the modifications made and the resulting absolute and relative change in $\mathrm{E}_{\text {total }}$. 
The sign of the changes are as expected: Higher SZA mainly has an impact on the cloud free scenes, increasing the light paths, and hence the visibility for the free troposphere. Absorbing properties of the cloud droplets $(\mathrm{SSA}<1)$ lead to lower AMFs below the clouds due to more effective shielding, and thus lower sensitivity. If the scattering would be more/less diffusive $(g=0.8 / 0.9)$, generally less/more photons will penetrate the clouds "forth and back". A lower/higher ground albedo decreases/increases the visibility of the lower layers.

The relative change in sensitivity, however, is rather small for all cases. Hence, none of the assumptions is critical for our conclusions. The parameterization of extinction from the modelled hydrometeors (Eq. 14); see Platt, 1997) is not critical, either. A doubling/halving of the extinction coefficients results in optically thicker/thinner clouds and hence more/less effective shielding, i.e. lower/higher sensitivities. The relative changes are significant $(-13 \%$ and $+19 \%$, respectively), but still rather moderate.

\subsubsection{Uncertainties of the calculation of synthetic slant columns and sensitivities}

For the calculation of sensitivities according to Eq. (15), the model profiles have to be corrected with respect to the "clean" background columns. These backgrounds have to be estimated from the model run itself. Taking the $1 \%$ "cleanest" scenes is a good working solution for the estimation of background $\mathrm{NO}_{\mathrm{x}}$. This background estimate is rather conservative to avoid negative concentrations. As a consequence, large regions of the simulated OTS that should be "clean" still show VCDs of some $10^{13} \mathrm{molec} / \mathrm{cm}^{2}$ of $\mathrm{LNO}_{\mathrm{x}}$ (compare Fig. 8). For our analysis of individual sensitivities per scene, the impact of a possible background bias is minimized by the applied threshold of $10^{14} \mathrm{molec} / \mathrm{cm}^{2}$ for $\mathrm{LNO}_{\mathrm{x}}$. For the calculation of $\mathrm{E}_{\text {total }}$, the impact of background is also rather small, since the integrated column densities are dominated by scenes with high columns. In addition, the difference of the sensitivities for background- and for lightning $\mathrm{NO}_{\mathrm{x}}$ is rather small for cloud free scenes.

For the background correction of $\mathrm{NO}_{2}$ profiles, we subtract the background $\mathrm{NO}_{\mathrm{x}}$ from the total $\mathrm{NO}_{\mathrm{x}}$ profile, and split the corrected $\mathrm{NO}_{\mathrm{x}}$ profile to $\mathrm{NO}$ and $\mathrm{NO}_{2}$ according to the original model partitioning (note that we can not simply subtract the background $\mathrm{NO}_{2}$ profiles that are valid for cloud free scenes only!). I.e., we assume that the background $\mathrm{NO}_{\mathrm{x}}$, that would be present if there would not have been any $\mathrm{LNO}_{\mathrm{x}}$ production, would have the same partitioning as the actual model total $\mathrm{NO}_{\mathrm{x}}$. This approach neglects possible nonlinearities of the photochemistry due to additional $\mathrm{LNO}_{\mathrm{x}}$; however, for scenes where $\mathrm{LNO}_{\mathrm{x}}$ is much higher than the background, the latter is irrelevant anyway. On the other hand, if $\mathrm{LNO}_{\mathrm{x}}$ is low, it should not affect the $\mathrm{NO}_{\mathrm{x}}$ partitioning of the background.
In Appendix A, it is shown and discussed that the $\mathrm{NO}_{2}$ excess $\Delta \mathrm{S}^{\mathrm{NO}_{2}}$ for uncorrected profiles can be decreased and even become negative, if the shielding effect of the clouds for background $\mathrm{NO}_{\mathrm{x}}$ overcompensates the column increase due to lightning $\mathrm{NO}_{\mathrm{x}}$. In Fig. 10, we hence plot also $\mathrm{V}^{\mathrm{NO}}$, $\mathrm{S}^{\mathrm{NO}_{2}}$, and sensitivities for the original, uncorrected profiles. In (b) it can clearly be seen that for some regions of the OTS (generally speaking: where COT is high, but $\mathrm{LNO}_{\mathrm{x}}$ is low) the SCDs of $\mathrm{NO}_{2}$ are actually lower than the background. For these regions, the second term of Eq. (A3) is obviously not negligible. For relatively high background levels, $\mathrm{LNO}_{2}$ is thus likely to be "overseen" from space. Hence, the quantification of $\mathrm{LNO}_{\mathrm{x}}$ using satellite observations only has good prospects for events with high flash rates and low background $\mathrm{NO}_{\mathrm{x}}$.

In our study, we ignore the shielding of background $\mathrm{NO}_{\mathrm{x}}$. The resulting sensitivities are thus slightly biased for the thunderstorms under investigation, but should be appropriate for stronger thunderstorms with higher flash rates, which should be selected for quantitative studies, where background $\mathrm{NO}_{\mathrm{x}}$ can indeed be neglected.

\subsubsection{Representativeness}

In this study, a number of simulated mesoscale convective systems (MCSs) and isolated storms have been investigated in the TOGA COARE/CEPEX region over several days. During the simulation, different stages of MCS evolution are captured. Hence our study comprises the high spatial and temporal variabilities of convective systems.

The TOGA COARE/CEPEX region is located in the Pacific Warm Pool, where deep convection is very frequent, with an annual maximum in January/February. Especially during the seven day episode from 19-26 December 1992, relatively high flash rates have been simulated due to frequent deep convection associated with the onset of a westerly phase of the Intra-Seasonal Oscillation (e.g. Salzmann et al., 2004). The simulated peak flash rates per storm are nevertheless at least an order of magnitude below those observed during vigorous continental thunderstorms. However, tropical marine convective systems are the first choice for studies of fresh $\mathrm{LNO}_{\mathrm{x}}$, since the background $\mathrm{NO}_{\mathrm{x}}$ is generally lower, and the diurnal cycle of flash activity is less dominated by late afternoon as for continental lightning, i.e. more occurrences during the currently available satellite overpasses can be found.

The simulated mesoscale convective systems and individual thunderstorm reflect the general features of tropical marine thunderstorm dynamics, (photo-) chemistry, and profiles of hydrometeors and $\mathrm{LNO}_{\mathrm{x}}$. Our results are robust with respect to modifications of RTM settings and even moderate perturbations of the simulated $\mathrm{NO}_{\mathrm{x}}$ profiles. Hence our results are likely representative for tropical marine thunderstorms. However, the question remains open, how far 

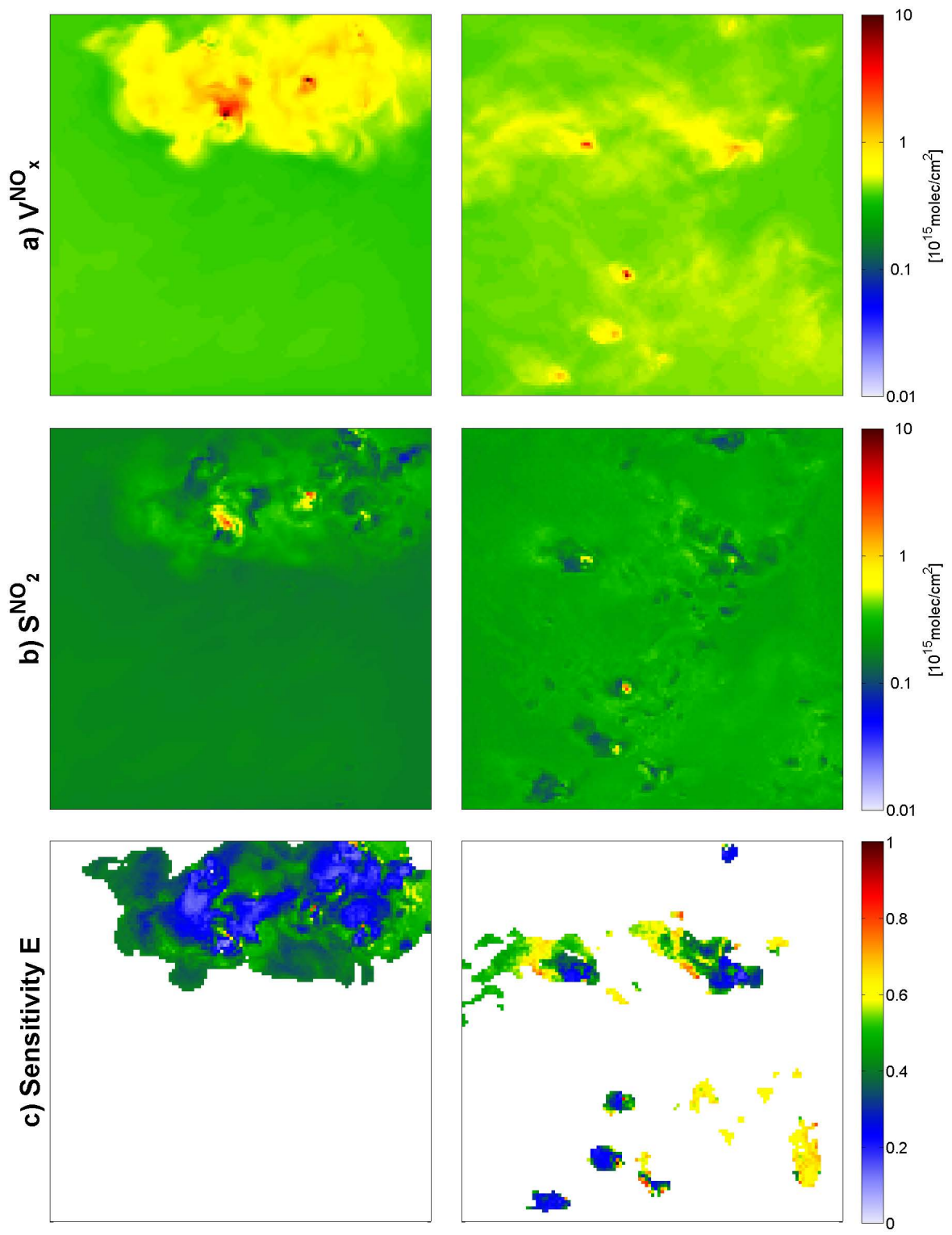

Fig. 10. As Fig. 8, but for the non-corrected columns $\mathrm{V}^{\mathrm{NO}}$ (a) and $\mathrm{S}^{\mathrm{NO}_{2}}$ (b). Panel (c) displays sensitivities $\mathrm{E}=\mathrm{S}^{\mathrm{NO}_{2}} / \mathrm{V}^{\mathrm{NO}} \mathrm{x}$ of total columns (Eq. 9), while Fig. 8c displays $\mathrm{E}^{L}=\mathrm{S}^{\mathrm{LNO}_{2} / \mathrm{V}^{\mathrm{LNO}}}$ (Eq. 12). Due to the rather low $\mathrm{LNO}_{\mathrm{x}}$ columns, the shielding of background $\mathrm{NO}_{\mathrm{x}}$ is clearly visible for some scenes in (b), leading to a negative response of $\Delta \mathrm{S}^{\mathrm{NO}_{2}}$ to lightning. Note, however, that there are also regions where $\mathrm{E}$ is higher than $\mathrm{E}^{L}$. Total sensitivities from total columns are 0.40 and 0.57 , respectively.

estimates of $\mathrm{LNO}_{\mathrm{x}}$ production based on tropical marine thunderstorms can be extrapolated to global scale.

Further studies will be required in order to investigate the representativeness of our study, involving additional thunderstorm simulations, probably also with additional cloud resolving- and radiative transfer models.

\subsection{Implications}

Our study results in a mean total sensitivity of 0.46 for lightning $\mathrm{NO}_{\mathrm{x}}$. The synthetic satellite SCDs of $\mathrm{LNO}_{2}$ reach values up to $5 \times 10^{15} \mathrm{molec} / \mathrm{cm}^{2}$ for single $2 \times 2 \mathrm{~km}^{2}$ pixels.
However, for a resolution of $30 \times 30 \mathrm{~km}^{2}$, maximum $\mathrm{S}^{\mathrm{LNO}_{2}}$ is only about $2 \times 10^{14} \mathrm{molec} / \mathrm{cm}^{2}$ above background. This implies that the $\mathrm{LNO}_{\mathrm{x}}$ production of the analyzed thunderstorms probably would not have been visible for an instrument like SCIAMACHY. However, if the retrieved sensitivity of 0.46 is representative for thunderstorms globally, then a number of e.g. 250 flashes within a SCIAMACHY pixel $\left(30 \times 60 \mathrm{~km}^{2}\right)$ would lead to an enhancement of $\mathrm{S}^{\mathrm{NO}_{2}}$ of $10^{15} \mathrm{molec} / \mathrm{cm}^{2}$, which should be clearly visible from space. (Note that in the WWLLN data for 2004-2006, we found 338 SCIAMACHY pixels with more than 250 flash counts, and 5676 pixels with more than 25 flash counts within the 
last $60 \mathrm{~min}$ prior the satellite overpass. These flash counts have to be scaled up by a factor of more than 5-10, since the WWLLN detection efficiency is about 10-20\% around Australia and Indonesia, and far below 5\% for South America and Africa (Rodger et al., 2006)). For this estimate we assumed a mean $\mathrm{LNO}_{\mathrm{x}}$ production of $15 \times 10^{25} \mathrm{molec}$ $\left[\mathrm{NO}_{\mathrm{x}}\right]$ per flash, as given as best estimate in Schumann and Huntrieser (2007), corresponding to a global $\mathrm{LNO}_{\mathrm{x}}$ production of $5 \mathrm{Tg}\left[\mathrm{NO}_{\mathrm{x}}\right]$ per year. However, previous estimates of $\mathrm{LNO}_{\mathrm{x}}$ production using satellite data (Beirle et al., 2004, 2006; Boersma et al., 2005; Martin et al., 2007) generally find lower estimates. Moreover, if we use the resulting sensitivity derived in this study to update the results of Beirle et al. (2006), in which a constant sensitivity of 0.25 was estimated and applied, we estimate a total $\mathrm{LNO}_{\mathrm{x}}$ production of only 0.9 (instead of 1.7) $\mathrm{Tg}$ per year, or 2.9 (instead of 5.4) $\times 10^{25}$ molec $\left[\mathrm{NO}_{\mathrm{x}}\right]$ per flash. In addition, preliminary estimates of fresh lightning $\mathrm{NO}_{\mathrm{x}}$ from SCIAMACHY measurements over active thunderstorms (as indicated by WWLLN measurements) are much lower than would be expected for an actual release of $15 \times 10^{25} \mathrm{molec}$ $\left[\mathrm{NO}_{\mathrm{x}}\right]$ per flash. This discrepancy to other studies (Schumann and Huntrieser, 2007, and references therein) might indicate that the global lightning production is currently overestimated. Hence, further studies of fresh $\mathrm{LNO}_{\mathrm{x}}$ from satellites could potentially lead to a constraint on the upper bound of total $\mathrm{NO}_{\mathrm{x}}$ production by lightning. However, the discrepancies could also indicate systematic regional and/or temporal differences of the mean $\mathrm{LNO}_{\mathrm{x}}$ production per flash. For instance, Huntrieser et al. (2008) suggest that tropical thunderstorms are less effective in $\mathrm{LNO}_{\mathrm{x}}$ production per flash due to lower wind shears, resulting in smaller stroke lengths. One has also to keep in mind that the local overpass times of current satellite instruments are before (GOME, SCIAMACHY, GOME-2) or shortly after (OMI) noon, and thus miss the maximum of lightning activity over tropical land masses in the late afternoon.

\section{Conclusions}

For the first time, we investigated the sensitivity of nadir viewing satellite instruments for freshly produced lightning $\mathrm{NO}_{\mathrm{x}}$ under conditions simulated in and around cumulonimbus clouds, considering (photo-) chemistry and radiative transfer consistently. From our study, we come to the following conclusions:

1. The box-AMFs $a_{i}$ for $\mathrm{NO}_{2}$ in cumulonimbus clouds are close to stratospheric values above the cloud, jump to values up to 5 at the cloud top, and decrease towards the ground, but can still reach values of 1 several $\mathrm{km}$ below the cloud top. Below the cloud bottom, $a_{i}$ is close to zero. These results are similar to those shown in Hild et al. (2002).
2. Since $\mathrm{NO}_{\mathrm{x}}$ at the tropopause is almost all present as $\mathrm{NO}$ (on average $95 \%$ at $15 \mathrm{~km}$ ), but only $\mathrm{NO}_{2}$ can be detected in UV-vis spectra, the visibility for $\mathrm{NO}_{\mathrm{x}}\left(e_{i}\right)$ is low (0.2) at the cloud top, highest (1-2) in the cloud middle or even at the cloud bottom, and low $(0-0.5)$ below the cloud. This simply means: $\mathrm{NO}_{\mathrm{x}}$ below the cloud is shielded, $\mathrm{NO}_{\mathrm{x}}$ above the cloud is photolysed, but $\mathrm{NO}_{\mathrm{x}}$ inside the cloud can be seen well from space.

3. Individual sensitivities $\mathrm{E}$ vary due to the thunderstorm dynamics. Lowest values are found where $\mathrm{NO}_{\mathrm{x}}$ peaks below or above the cloud, whereas $\mathrm{E}$ is highest for $\mathrm{NO}_{\mathrm{x}}$ within the cloud.

4. The overall variability of $E$ in time and space is rather small (given the large variability of thunderstorm dynamics).

5. On average, observations over anvils show the lowest sensitivities.

6. Total (i.e. spatially averaged, Eq. 15) sensitivity is 0.46 $(\sigma=0.09)$ (mean of all OTSs).

7. Lightning produced $\mathrm{LNO}_{\mathrm{x}}$ lead to very high $\mathrm{NO}_{\mathrm{x}}$ concentrations within the lightning channel, resulting in extreme horizontal gradients in the $\mathrm{NO}_{\mathrm{x}}$ columns. Hence, improved spatial resolution of future nadir UV-vis satellite instruments is not only favourable for studying ground sources, but in particular for $\mathrm{LNO}_{\mathrm{x}}$.

8. Our results are robust with respect to modifications of RTM settings, and even to moderate perturbations to the simulated $\mathrm{NO}_{\mathrm{x}}$ profiles.

9. Our results are derived, and only valid, for scenarios of low tropospheric background levels of $\mathrm{NO}_{\mathrm{x}}$. Otherwise, the shielding of boundary layer $\mathrm{NO}_{\mathrm{x}}$ can even result in a negative response of the observed $\mathrm{NO}_{2}$ excess to lightning, and quantitative estimates are not possible.

10. From our results, a satellite measurement with a footprint of e.g. $30 \times 60 \mathrm{~km}^{2}$ (nominal SCIAMACHY resolution) over a thunderstorm/MCS generating 250 flashes should lead to an increase in the $\mathrm{NO}_{2} \mathrm{SCD}$ of $10^{15} \mathrm{molec} / \mathrm{cm}^{2}$, assuming a $\mathrm{LNO}_{\mathrm{x}}$ production of $15 \times 10^{25}$ molec $\left[\mathrm{NO}_{\mathrm{x}}\right]$ per flash, (if outflow can be neglected), i.e., must be observable from space. Preliminary comparisons of satellite observations with flash counts, however, indicate significantly lower $\mathrm{LNO}_{\mathrm{x}}$ production. Hence, future studies of $\mathrm{LNO}_{\mathrm{x}}$ using nadir viewing satellite data potentially provide an upper bound for global $\mathrm{LNO}_{\mathrm{x}}$ production.

Finally, future studies will be needed to reveal how representative this case study is with respect to global lightning, at least to the extent that this is possible, given the difficulties for regions with non-negligible background levels of $\mathrm{NO}_{\mathrm{x}}$. In 
this respect, a satellite instrument on a late afternoon orbit, or a geostationary satellite, allowing selected continental thunderstorms with high flash rates at low background (e.g. in the Congo basin) to be studied, would be of particular value.

\section{Appendix A}

\section{Impact of background $\mathrm{NO}_{\mathrm{x}}$}

In Eq. (12), $\mathrm{S}^{\mathrm{LNO}_{2}}$ is calculated from $\mathrm{E}^{\mathrm{L}}$ and $\mathrm{V}^{\mathrm{NO}_{x}}$. In a real measurement, the $\mathrm{NO}_{2}$ excess $\Delta \mathrm{S}^{\mathrm{NO}_{2}}$ (see Eq. 11), however, is the quantity that can be derived. Here we give a relation of $\Delta \mathrm{S}^{\mathrm{NO}_{2}}$ and $\mathrm{S}^{\mathrm{LNO}_{2}}$.

Starting from Eq. (11), we find

$$
\Delta \mathrm{S}^{\mathrm{NO}_{2}}:=\mathrm{S}^{\mathrm{NO}_{2}}-\mathrm{S}^{0}=\mathrm{V}^{\mathrm{NO}_{\mathrm{x}}} \cdot \sum e_{i}^{*} \cdot p_{i}^{*}-\mathrm{V}^{0} \cdot \sum e_{i}^{0} \cdot p_{i}^{0}
$$

The asterisk shall indicate that visibilities as well as profiles of the actual scenario might differ from background conditions (labelled by superscript ${ }^{0}$ ), for instance due to clouds.

We now split $\mathrm{V}^{\mathrm{NO}_{\mathrm{x}}}$ in $\mathrm{V}^{\mathrm{LNO}_{\mathrm{x}}}$ and $\mathrm{V}^{0}$ according to Eq. (10):

$$
\Delta \mathrm{S}^{\mathrm{NO}_{2}}=\mathrm{V}^{\mathrm{LNO}_{\mathrm{x}}} \cdot \sum e_{i}^{*} \cdot p_{i}^{\mathrm{L}}+\mathrm{V}^{0} \cdot \sum e_{i}^{*} \cdot \tilde{p}_{i}^{0}-\mathrm{V}^{0} \cdot \sum e_{i}^{0} \cdot p_{i}^{0}
$$

Note that the profile of the background $\mathrm{NO}_{\mathrm{x}}$ can also be modified (due to convection). The modified profile of background $\mathrm{NO}_{\mathrm{x}}$ is indicated by the tilde.

The first summand is identical with $\mathrm{S}^{\mathrm{LNO}_{2}}$ (see Eq. 12) for $e_{i}^{*}=e_{i}^{L}$, i.e. if the partitioning of $\mathrm{NO}_{\mathrm{x}}$ remains unaffected after removing the background, which is assumed in our analysis (see discussion in Sect. 4.1.3).

The terms containing $\mathrm{V}^{0}$ can be summarized as:

$$
\left.\Delta \mathrm{S}^{\mathrm{NO}_{2}}=\mathrm{S}^{\mathrm{LNO}_{2}}+\mathrm{V}^{0} \cdot\left(\mathrm{E}^{*, 0}-\mathrm{E}^{0}\right)\right)
$$

$\mathrm{E}^{0}$ is the sensitivity to background $\mathrm{NO}_{\mathrm{x}}$ under background (clear) conditions. $\mathrm{E}^{*, 0}$ is the sensitivity to background $\mathrm{NO}_{\mathrm{x}}$ (with modified profile $p^{\sim 0}$ ) under modified (clouded) conditions $\left(e^{*}\right)$. The difference $\mathrm{E}^{*, 0}-\mathrm{E}^{0}$ reflects the change of sensitivity for background $\mathrm{NO}_{\mathrm{x}}$ due to the change in viewing conditions (clouds) for thunderstorms.

Note that

1. the stratosphere plays no role in our considerations, since here we have no change of sensitivity $\left(\mathrm{E}^{*, 0} \approx \mathrm{E}^{0}\right)$.

2. the second term of Eq. (A3) can be both, positive and negative, depending on the change of sensitivity. In general, we expect a shielding effect $\left(\mathrm{E}^{*, 0}<\mathrm{E}^{0}\right)$, but convection could also increase the net sensitivity $\left(\mathrm{E}^{*, 0}>\mathrm{E}^{0}\right)$.

3. for relatively low values of $\mathrm{S}^{\mathrm{LNO}_{2}}$ and high values of $\mathrm{V}^{0}$, the shielding can actually lead to a negative response $\left(\Delta \mathrm{S}^{\mathrm{NO}_{2}}<0\right)$ to lightning $\mathrm{NO}_{\mathrm{x}}$ !
4. for scenes that are dominated by lightning $\mathrm{NO}_{\mathrm{x}}$, the second term of Eq. (A3) is negligible, and

$$
\Delta \mathrm{S}^{\mathrm{NO}_{2}} \approx \mathrm{S}^{\mathrm{LNO}_{2}}
$$

for low $\mathrm{V}^{0}$.

Acknowledgements. This project is funded by the DFG (Deutsche Forschungsgemeinschaft, German research society). The authors thank Tim Deutschmann for the valuable work on the RTM model McArtim and support in running it.

Edited by: R. Cohen

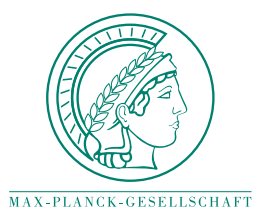

This Open Access Publication is financed by the Max Planck Society.

\section{References}

Beirle, S., Platt, U., Wenig, M., and Wagner, T.: $\mathrm{NO}_{\mathrm{x}}$ production by lightning estimated with GOME, Adv. Space Res., 34(4), 793797, 2004.

Beirle, S., Spichtinger, N., Stohl, A., Cummins, K. L., Turner, T., Boccippio, D., Cooper, O. R., Wenig, M., Grzegorski, M., Platt, U., and Wagner, T.: Estimating the $\mathrm{NO}_{\mathrm{x}}$ produced by lightning from GOME and NLDN data: a case study in the Gulf of Mexico, Atmos. Chem. Phys., 6, 1075-1089, 2006, http://www.atmos-chem-phys.net/6/1075/2006/.

Boccippio, D. J., Cummins, K. L., Christian, H. J., and Goodman, S. J.: Combined Satellite- and Surface-Based Estimation of the Intracloud-Cloud-to-Ground Lightning Ratio over the Continental United States, Mon. Weather Rev., 129, 108-122, 2000.

Boersma, K. F., Eskes, H. J., Meijer, E. W., and Kelder, H. M.: Estimates of lightning $\mathrm{NO}_{\mathrm{x}}$ production from GOME satellite observations, Atmos. Chem. Phys., 5, 2311-2331, 2005, http://www.atmos-chem-phys.net/5/2311/2005/.

Bovensmann, H., Burrows, J. P., Buchwitz, M., Frerick, J., Noël, S., Rozanov, V. V., Chance, K. V., and Goede, A. P. H.: SCIAMACHY: Mission objectives and measurement modes, J. Atmos. Sci., 56(2), 127-150, 1999.

Burrows, J., Weber, M., Buchwitz, M., Rozanov, V. V., LadstädterWeissenmayer, A., Richter, A., de Beek, R., Hoogen, R., Bramstedt, K., Eichmann, K.-U., Eisinger, M., and Perner, D.: The Global Ozone Monitoring Experiment (GOME): Mission concept and first scientific results, J. Atmos. Sci., 56, 151-175, 1999.

Christian, H. J., Blakeslee, R. J., Boccippio, D. J., et al.: Global frequency and distribution of lightning as observed from space by the Optical Transient Detector, J. Geophys. Res., 108, 4005, doi:10.1029/2002JD002347, 2003.

DeCaria, A. J., Pickering, K. E., Stenchikov, G. L., Scala, J. R., Stith, J. L., Dye, J. E., Ridley, B. A., and Laroche, P.: A cloudscale model study of lightning-generated $\mathrm{NO}_{\mathrm{x}}$ in an individual thunderstorm during STERAO-A, J. Geophys. Res., 105, 1160111616, 2000. 
DeCaria, A. J., Pickering, K. E., Stenchikov, G. L., and Ott, L. E.: Lightning-generated $\mathrm{NO}_{\mathrm{x}}$ and its impact on tropospheric ozone production: A three-dimensional modeling study of a Stratosphere-Troposphere Experiment: Radiation, Aerosols and Ozone (STERAO-A) thunderstorm, J. Geophys. Res., 110, D14303, doi:10.1029/2004JD005556, 2005.

Deutschmann, T. and Wagner, T.: TRACY-II Users manual, http: //joseba.mpch-mainz.mpg.de/Strahlungstransport.htm, 2006.

Deutschmann, T.: Atmospheric radiative transfer modelling using Monte Carlo methods, Diploma Thesis, Universität Heidelberg, 2009.

Dye, J. E., Ridley, B. A., Skamarock, W., Barth, M., Venticinque, M., Defer, E., Blanchet, P., Thery, C., Laroche, P., Baumann, K., Hubler, G., Parrish, D. D., Ryerson, T., Trainer, M., Frost, G., Holloway, J. S., Matejka, T., Bartels, D., Fehsenfeld, F. C., Tuck, A., Rutledge, S. A., Lang, T., Stith, J., and Zerr, R.: An overview of the Stratospheric-Tropospheric Experiment: Radiation, Aerosols and Ozone (STERAO)-Deep Convection experiment with result from the July 10, 1996 storm, J. Geophys. Res., 105, 10023-10045, 2000.

Fehr, T., Höller, H., and Huntrieser, H.: Model study on production and transport of lightning-produced $\mathrm{NO}_{\mathrm{x}}$ in a EULINOX supercell storm, J. Geophys. Res., 109, D09102, doi:10.1029/2003JD003935, 2004.

Hild, L., Richter, A., Rozanov, V., and Burrows, J. P.: Air Mass Calculations for GOME Measurements of lightning-produced $\mathrm{NO}_{2}$, Adv. Space Res., 29(11), 1685-1690, 2002.

Huntrieser, H., Schumann, U., Schlager, H., Hller, H., Giez, A., Betz, H.-D., Brunner, D., Forster, C., Pinto Jr., O., and Calheiros, R.: Lightning activity in Brazilian thunderstorms during TROCCINOX: implications for NOx production, Atmos. Chem. Phys., 8, 921-953, 2008, http://www.atmos-chem-phys.net/8/921/2008/.

Jöckel, P., Tost, H., Pozzer, A., Brühl, C., Buchholz, J., Ganzeveld, L., Hoor, P., Kerkweg, A., Lawrence, M. G., Sander, R., Steil, B., Stiller, G., Tanarhte, M., Taraborrelli, D., van Aardenne, J., and Lelieveld, J.: The atmospheric chemistry general circulation model ECHAM5/MESSy1: consistent simulation of ozone from the surface to the mesosphere, Atmos. Chem. Phys., 6, 50675104, 2006, http://www.atmos-chem-phys.net/6/5067/2006/.

von Kuhlmann, R., Lawrence, M. G., Crutzen, P. J., and Rasch, P. J.: A model for studies of tropospheric ozone and nonmethane hydrocarbons: Model description and ozone results, J. Geophys. Res., 108(D9), 4294, doi:10.1029/2002JD002893, 2003.

Labrador, L. J., von Kuhlmann, R., and Lawrence, M. G. : The effects of lightning-produced $\mathrm{NO}_{\mathrm{x}}$ and its vertical distribution on atmospheric chemistry: sensitivity simulations with MATCHMPIC, Atmos. Chem. Phys., 5, 1815-1834, 2005, http://www.atmos-chem-phys.net/5/1815/2005/.

Levelt, P. F., van den Oord, G. H. J., Dobber, M. R., Malkki, A., Visser, H., de Vries, J., Stammes, P., Lundell, J. O. V., and Saari, H.: The ozone monitoring instrument, IEEE T. Geosci. Remote, 44, 5, 1093-1101, 2006.

Marchuk, G., Mikhailov, G., Nazaraliev, M., Darbinjan, R., Kargin, B., and Elepov, B.: The Monte Carlo Methods in Atmospheric Optics, Springer-Verlag Berlin, 208 pp., 1980.

Marshak, A., Davis, A., Cahalan, R. F., and Wiscombe, W., Nonlocal Independent Pixel Approximation: Direct and Inverse Prob- lems, IEEE T. Geosci. Remote, 36, 1, 192-205, 1998.

Martin, R. V., Sauvage, B., Folkins, I., Sioris, C. E., Boone, C., Bernath, P., and Ziemke, J.: Space-based constraints on the production of nitric oxide by lightning, J. Geophys. Res., 112, D09309, doi:10.1029/2006JD007831, 2007.

Ott, L. E., Pickering, K. E., Stenchikov, G. L., Huntrieser, H., and Schumann, U.: Effects of lightning $\mathrm{NO}_{\mathrm{x}}$ production during the 21 July European Lightning Nitrogen Oxides Project storm studied with a three-dimensional cloud-scale chemical transport model, J. Geophys. Res., 112, D05307, doi:10.1029/2006JD007365, 2007.

Pickering, K. E., Wang, Y., Tao, W.-K., Price, C., and Müller, J.F.: Vertical distributions of lightning $\mathrm{NO}_{\mathrm{x}}$ for use in regional and global chemical transport models, J. Geophys. Res., 103, 3120331216, 1998.

Pierce, E. T.: Latitudinal variation of lightning parameters, J. Appl. Metalwork, 9, 194-195, 1970.

Platt, C. M. R.: A parameterization of the visible extinction coefficitent of ice clouds in terms of the ice/water content, J. Atmos. Sci., 54, 2083-2098, 1997.

Price, C. and Rind, D.: A simple lightning parameterization for calculating global lightning distributions, J. Geophys. Res., 97, 9919-9933, 1992.

Price, C. and Rind, D.: What determines the cloud-to-ground lightning fraction in thunderstorms?, Geophys. Res. Lett., 20, 463466, 1993.

Ray, P. S., MacGorman, D. R., Rust, W. D., Taylor W. L., and Walters Rasmussen, L.: Lightning location relative to storm structure in a supercell and a multicell storm, J. Geophys. Res., 92, 57135724, 1987.

Ridley, B. A., Dye, J. E., Walega, J. G., Zheng, J., Grahek, F. E., and Rison, W.: On the production of active nitrogen by thunderstorms over New Mexico, J. Geophys. Res., 101, 20985-21005, 1996.

Rodger, C. J., Werner, S., Brundell, J. B., Lay, E. H., Thomson, N. R., Holzworth, R. H., and Dowden, R. L.: Detection efficiency of the VLF World-Wide Lightning Location Network (WWLLN): Initial case study, Ann. Geophys., 24, 3197-3214, 2006, http://www.ann-geophys.net/24/3197/2006/.

Salzmann, M., Lawrence, M. G., Phillips, V. T. J., and Donner, L. J.: Modelling tracer transport by a cumulus ensemble: Lateral boundary conditions and large-scale ascent, Atmos. Chem. Phys., 4, 1797-1811, 2004,

http://www.atmos-chem-phys.net/4/1797/2004/.

Salzmann, M., Lawrence, M. G., Phillips, V. T. J., and Donner, L. J.: Cloud system resolving model study of the roles of deep convection for photo-chemistry in the TOGA COARE/CEPEX region, Atmos. Chem. Phys., 8, 2741-2757, 2008, http://www.atmos-chem-phys.net/8/2741/2008/.

Schumann, U. and Huntrieser, H.: The global lightning-induced nitrogen oxides source, Atmos. Chem. Phys., 7, 3823-3907, 2007, http://www.atmos-chem-phys.net/7/3823/2007/.

Skamarock, W. C., Klemp, J. B., and Dudhia, J: Prototypes for the WRF (Weather Research and Forecasting) model, in: Preprints, Ninth Conf. Mesoscale Processes, Am. Meteor. Soc., Fort Lauderdale, FL, J11-J15, 2001.

Tost, H., Jöckel, P., and Lelieveld, J.: Lightning and convection parameterisations - uncertainties in global modelling, Atmos. Chem. Phys., 7, 4553-4568, 2007, 
http://www.atmos-chem-phys.net/7/4553/2007/.

Wagner, T., Burrows, J. P., Deutschmann, T., Dix, B., von Friedeburg, C., Frie, U., Hendrick, F., Heue, K.-P., Irie, H., Iwabuchi, H., Kanaya, Y., Keller, J., McLinden, C. A., Oetjen, H., Palazzi, E., Petritoli, A., Platt, U., Postylyakov, O., Pukite, J., Richter, A., van Roozendael, M., Rozanov, A., Rozanov, V., Sinreich, R., Sanghavi, S., and Wittrock, F.: Comparison of box-airmass-factors and radiances for Multiple-Axis Differential Optical Absorption Spectroscopy (MAX-DOAS) geometries calculated from different UV/visible radiative transfer models, Atmos. Chem. Phys., 7, 1809-1833, 2007,

http://www.atmos-chem-phys.net/7/1809/2007/.
Wagner, T., Beirle, S., Deutschmann, T., Eigemeier, E., Frankenberg, C., Grzegorski, M., Liu, C., Marbach, T., Platt, U., and Penning de Vries, M.: Monitoring of atmospheric trace gases, clouds, aerosols and surface properties from UV/vis/NIR satellite instruments, J. Opt. A., Pure Appl. Opt., 10, 104019, doi:10.1088/1464-4258/10/10/104019, 9 pp., 2008.

Webster, P. J. and Lukas, R.: TOGA COARE: The Coupled OceanAtmosphere Response Experiment, B. Am. Meteorol. Soc., 73, 1377-1416, 1992.

Wenig, M., Kühl, S., Beirle, S., Bucsela, E., Jähne, B., Platt, U., Gleason, J., and Wagner, T.: Retrieval and analysis of stratospheric $\mathrm{NO}_{2}$ from the Global Ozone Monitoring Experiment, J. Geophys. Res., 109, D04315, doi:10.1029/2003JD003652., 2004. 